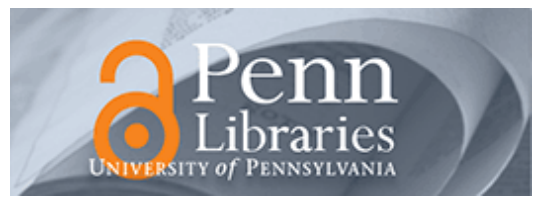

University of Pennsylvania

ScholarlyCommons

Accounting Papers

Wharton Faculty Research

$4-2016$

\title{
Institutional Investments in Pure Play Stocks and Implications for Hedging Decisions
}

\author{
Bernadette A. Minton \\ Catherine M. Schrand \\ University of Pennsylvania
}

Follow this and additional works at: https://repository.upenn.edu/accounting_papers

Part of the Accounting Commons, and the Corporate Finance Commons

\section{Recommended Citation}

Minton, B. A., \& Schrand, C. M. (2016). Institutional Investments in Pure Play Stocks and Implications for Hedging Decisions. Journal of Corporate Finance, 37132-151. http://dx.doi.org/10.1016/

j.jcorpfin.2015.12.013

This paper is posted at ScholarlyCommons. https://repository.upenn.edu/accounting_papers/11

For more information, please contact repository@pobox.upenn.edu. 


\title{
Institutional Investments in Pure Play Stocks and Implications for Hedging Decisions
}

\begin{abstract}
We show that institutions invest in stocks within an industry that maintain exposure to their underlying industry risk factor. These "pure play" stocks have greater numbers ofinstitutional investors and institutions systematically overweight them in their portfolios while underweighting low industry-exposure stocks of firms in the same nominal industry.Pure play stocks also have greater liquidity measured by stock turnover and price impact. An implication of these results is that catering to these preferences could be an important variable in firms' risk management decisions, potentially offsetting incentives to reduce volatility via hedging. We further characterize institutions' investments for pureplay stocks across institution type, industries, and over time.
\end{abstract}

\section{Keywords}

institutional investor, hedging, catering, pure play stocks

Disciplines

Accounting | Corporate Finance 


\section{Charles A. Dice Center for Research in Financial Economics \\ Institutional Investments in Pure Play Stocks and Implications for Hedging Decisions}

Bernadette A. Minton,

The Ohio State University

Catherine Schrand,

University of Pennsylvania

Dice Center WP 2016-3

Fisher College of Business WP 2016-03-03

February, 2016 


\title{
Institutional Investments in Pure Play Stocks \\ and
}

\author{
Implications for Hedging Decisions
}

\author{
Bernadette A. Minton \\ Fisher College of Business \\ The Ohio State University \\ 700E Fisher Hall \\ 2100 Neil Avenue \\ Columbus, $\mathrm{OH} 43210$ \\ (614) 688-3125 \\ minton.15@ fisher.osu.edu \\ Catherine Schrand \\ The Wharton School \\ University of Pennsylvania \\ 1316 SH-DH \\ Philadelphia, PA 19104 \\ (215) 898-6798 \\ schrand@wharton.upenn.edu
}

February 2016

\begin{abstract}
We acknowledge the significant contributions of Phil Davies, an author on previous versions of this paper. We are grateful to Brian Bushee for providing his data on institutional ownership classifications. We thank David Barker, Matt Billett, Brian Bushee, Eric Lie, Anand Vijh, Paul Zarowin and seminar participants at New York University, the London Business School, INSEAD, the University of Rochester, the University of Iowa, The Ohio State University, and Southern Methodist University for helpful suggestions. The authors thank the Global Association of Risk Professionals (GARP) for funding. Minton acknowledges financial support from the Dice Center for Research in Financial Economics.
\end{abstract}




\section{Institutional Investments in Pure Play Stocks and Implications for Hedging Decisions}

We show that institutions invest in stocks within an industry that maintain exposure to their underlying industry risk factor. These "pure play" stocks have greater numbers of institutional investors and institutions systematically overweight them in their portfolios while underweighting low industry-exposure stocks of firms in the same nominal industry. Pure play stocks also have greater liquidity measured by stock turnover and price impact. An implication of these results is that catering to these preferences could be an important variable in firms' risk management decisions, potentially offsetting incentives to reduce volatility via hedging. We further characterize institutions' investments for pure play stocks across institution type, industries, and over time. 


\section{Introduction}

The common view in the academic literature is that firms hedge to reduce cash flow variability, which is costly to the firm because of capital market imperfections such as agency costs, financial distress, and underinvestment (e.g. Stulz, 1984, Smith and Stulz, 1985, Froot, Scharfstein, and Stein, 1993). Textbook discussions of risk management similarly stress that hedging to reduce variability can make sense if it reduces the chance of cash shortfalls or financial distress (e.g. Brealey, Myers, and Allen, 2014; Berk and DeMarzo, 2014). The most commonly discussed force that can offset firms' incentives to reduce variability, especially for small firms, is fixed costs of running a risk management program (Nance, Smith and Smithson, 1993; Géczy, Minton, and Schrand, 1997). ${ }^{1}$

Empirical evidence, however, suggests that these explanations for corporate hedging may not be complete. Observed patterns in derivatives use are consistent with some of these rationales, but to different degrees and in different settings. ${ }^{2}$ In addition, there is the somewhat puzzling evidence about the predicted positive relationship between hedging and firm value. Commoditybased firms that manage their price risk do not have higher valuations than unhedged firms (Tufano, 1996, and Jin and Jorion, 2006) and there is mixed empirical evidence on the association between currency hedging and firm value (Allayannis and Weston, 2001 and Guay and Kothari, 2003).

Motivated by these partial explanations and puzzles, we propose that a missing variable in the risk management theories could be a clientele effect associated with exposure to the firm's underlying industry risk factor (i.e., being a "pure play" stock). When firms hedge the variability

\footnotetext{
${ }^{1}$ A recent exception is Rampini, Sufi, and Viswanathan (2014) who discuss collateral constraints as a mitigating force in risk management activities.

${ }^{2}$ For FX derivatives in particular, the Géczy et al. (1997) model predicts just over 70\% of hedgers accurately.
} 
that can negatively impact the firm's investing and financing choices, they also may be hedging away an exposure that investors want. Our proposition that institutional preferences for pure play stocks could be an important variable in firms' risk management decisions rests on two important assumptions. The first is that institutions systematically invest in stocks with exposure to an industry risk factor, and the second is that firms value institutional ownership, either for its monitoring or liquidity benefits (Chen, Harford, and Li, 2007). If the benefits that come from catering to these institutional investors are large enough, they could be an offsetting force that warrants not hedging.

We take as given the second assumption that firms might value institutional ownership enough that it could be a relevant factor in their risk management decisions. This supposition is based on insights from several areas of existing evidence. Studies show an association between liquidity and the cost of capital (e.g., Chordia, Subrahmanyam, and Anshuman, 2001; Chan, 2002; Pastor and Stambaugh, 2003; Acharya and Pedersen, 2005; and Wang, 2003), which provides a rationale for firms to value the liquidity provided from increased institutional ownership. In addition, studies suggest that firms cater to institutional preferences in other real activities including dividend policy and exchange listing (e.g., Baker and Wurgler, 2004; Doidge, Karolyi and Stulz, 2004). ${ }^{3}$ Finally, firms engage in costly activities intended to attract institutional investors, such as investor conferences, suggesting that they view institutional ownership as valuable.

\footnotetext{
${ }^{3}$ Anecdotal evidence suggests that managers consider the attractiveness of their stock to investors when making hedging choices. In an interview in 2002, Robert McEwen, chief executive of Goldcorp, stated: "Being number one and ultimate gold stock are not the same. So what is the ultimate gold stock? Low risk; superior assets; very profitable business; leverage to gold; a strong board and management group; and excellent growth prospects. We are North American based, we have no debt, we are not hedged, a quarter billion dollars in cash at the end of the first half." (emphasis added) McEwen (2002)
} 
We cannot, however, take as given the first assumption that institutions systematically invest in stocks with exposure to an industry risk factor. Whether and when institutions invest in pure play stocks is an open empirical question. ${ }^{4}$

Our goal is to address this question by characterizing institutions' investments in stocks that maintain high within-industry exposure to the underlying industry risk factor ("pure play" stocks) on average and across different industries, institution types, and through time. Our selection of characteristics to analyze is guided by commonly observed features of the institutional investment process that shape institutions' holdings decisions. These features include contractual arrangements in the delegated asset management industry that regularly include industry performance benchmarks and concentrations of information expertise about industry sectors. The idea that institutions would display preferences for exposure is generally intuitive given these features of the industry. ${ }^{5}$ We seek to understand the phenomenon in a more precise way.

We analyze two measures of institutional investments in pure play stocks. The first is the number of owners of a firm's stock. The second is the degree to which institutions tilt their portfolios toward (away from) high exposure (low exposure) stocks. Our primary measure of within-industry exposure is derived from a two-factor market model that includes an industryfactor, estimated annually within the Fama-French 30 industries.

We document robust evidence that institutions systematically invest in pure play stocks. Pure play stocks have 35\% more institutional investors, on average, than low-exposure stocks after controlling for other previously identified determinants of institutional ownership, and institutions

\footnotetext{
${ }^{4}$ Investors' preferences for intra-industry exposure are distinct from previously documented preferences for particular industries (e.g., Kacperczyk, Sialm, and Zheng, 2005). Not all "gold" stocks, for example, have the same degree of exposure to gold price risk due to differences in their underlying operations or hedging policies.

${ }^{5}$ In fact, the existence of the BUGS index (Basket of Unhedged Gold Stocks) provides anecdotal evidence that investors have preferences for industry exposures, at least within the gold industry.
} 
tilt their portfolios toward pure play stocks, overweighting (underweighting) high-exposure (lowexposure stocks) by 138 (142) basis points (bps) on average relative to the stock's value-weighted share in the industry portfolio. Investments in pure play stocks are strongest following periods of favorable industry news, with overweighting almost twice as large relative to periods following less favorable news. Pure play stock investments are concentrated in industries in which industry returns explain a large fraction of firm-level returns relative to the market ("high homogeneity industries" including utilities, mining, tobacco, crude oil/natural gas, and coal). In high homogeneity industries, institutions overweight high-exposure (underweight low-exposure) stocks by 388 (601) bps. We find little evidence of preferences for industry exposure in low homogeneity industries (i.e., wholesale, services, games, fabricated products, and electrical equipment).

While all institutions invest in pure play stocks, the strength of the association varies by institution type. We categorize institutions using two classification schemes. The first is the groupings specified by Thompson Financial: banks, insurance companies, investment advisors, and pensions/endowments. The second is the groupings based on observed trading activity (Bushee, 1998): dedicated owners, quasi-indexers, and transient investors. ${ }^{6}$ Both classification schemes help distinguish institutions based on whether their primary role is monitoring or providing liquidity. We find that institutional investments in pure play stocks are strongest for liquidity providers (e.g., investment advisors and transient investors) compared to institutions often characterized as providing monitoring, and the liquidity providers' preferences are strongest in the high homogeneity industries.

\footnotetext{
6 We thank Brian Bushee for making the institution classification data available on his website: http://acct.wharton.upenn.edu/faculty/bushee/IIclass.html Bushee (2011).
} 
The salient factor in a firm's risk management decision is not institutional ownership per se but the economic benefit that the institutional ownership provides. Although the benefits of institutional ownership could come from increased monitoring or increased liquidity in the firm's stock, we cannot measure the economic benefits of increased monitoring in a systematic fashion. We can, however, estimate the association between liquidity and industry exposure, which is useful given the previously documented finding that institutions classified as liquidity providers show the strongest preferences for pure play stocks. We document that share turnover is $45 \%$ higher (29\% lower) for pure play (low exposure) stocks than for stocks with medium levels of exposure, and price impact (Amihud, 2002) is $47 \%$ lower (61\% higher) for pure play (low exposure) stocks. These results suggest that the relation between exposure and liquidity is measurable and economically meaningful.

We use a comprehensive sample and sample period. Our sample firms include all stocks that are owned by at least one institution that files a $13 \mathrm{~F}$ and that have Compustat and CRSP data available, thus we cover a comprehensive set of publicly-traded firms. We conduct the analysis over the years $1984-2006$, a long period that can encompass variation in stock market trends including periods of momentum and changes in the structure of the fund industry such as the introduction of ETFs. We subject the analysis to multiple robustness tests. The findings are robust to alternative measures of exposure and they are not explained by firm characteristics that are potentially correlated with industry exposure including idiosyncratic risk, liquidity, firm size, and financial reporting transparency.

One implication of our analyses is that a risk management program intended to reduce cash flow variability also could hedge away industry exposure, which is desired by institutional investors. We are not, however, proposing that this evidence implies that firms should hedge less, 
or in the extreme, not hedge. We are proposing that firms should weigh the potential benefits of increased institutional investment in the firm's stock against the benefits that hedging can convey by reducing cash flow variability. Our findings shed light on the industries that could see the greatest increase in institutional investment by being a pure play stock, as well as when the response could be greatest and from which types of institutions.

The paper proceeds as follows. Section 2 discusses existing studies that connect to the analysis. Section 3 describes the measurement of intra-industry exposure. Section 4 presents the analysis of institutional ownership and of portfolio tilting, on average, including various robustness tests. Section 5 presents evidence on the economic benefits of being a pure play stock. Section 6 provides cross-sectional evidence on which industries, periods of time and for which types of institutions the investments in pure play stocks are more pronounced. Section 7 concludes.

\section{Related literature}

A fairly robust finding in the literature is that institutional investors make investment decisions based on firm characteristics. Commonly accepted characteristics include market capitalization (e.g., Gompers and Metrick, 2001; Bennett, Sias, and Starks, 2003; Blume and Keim, 2014); "style" characteristics such as growth or value (Barberis and Shleifer, 2003); and dividend policy (Del Guercio, 1996). A firm's industry is another example. Industry concentration is

explained by institutions' incentives to exploit information advantages (Kaperczyk, Sialm, and Zheng, 2005). Yet, studies have not examined whether institutions make investment decisions among firms within an industry based on a firm's exposure to the underlying industry factor.

One rationale for institutional investment in pure play stocks is the common practice in the delegated asset management industry of including industry performance benchmarks in customer 
contracts. In particular, for advisors of regulated assets (i.e., mutual funds), the SEC requires funds to report performance relative to a broad-based benchmark, such as the S\&P500, in the registration statement (Form N1-A), and funds may report their performance relative to one or more other indexes, such as an industry index. Performance benchmarking is voluntary outside regulated funds, but moral hazard and adverse selection models predict benchmarking as an optimal choice (e.g., Maug and Naik, 1996). Whether regulated or self-imposed, benchmarks could affect the fund manager's investment allocation decisions either directly though relative performance in compensation contracts or indirectly because compensation is based on assets under management and performance relative to a benchmark affects fund flows (e.g., Sirri and Tufano, 1998; Sensoy, 2009).

At the same time, asset managers can have limits on the scale and scope of their investments, including prohibitions against holding assets or trading financial instruments such as derivatives. Given these trading constraints, which again can be regulated or self-imposed, ${ }^{7}$ a cost effective way for institutions to meet their stated performance objectives is to invest in stocks that are exposed to the relevant industry factors.

Our analysis also is guided by theories of endogenous information gathering. These "learning" models predict that investors with greater information processing capacity (i.e., less constrained) will engage in specialized information acquisition about common risk factors that affect the payoffs to multiple risky assets (Peng and Xiong, 2006; Van Nieuwerburgh and Veldkamp, 2010). Having acquired the information, the investor subsequently allocates more

\footnotetext{
${ }^{7}$ Mutual funds, in particular, are required to include in the registration statement their overall investment objective and their strategy to achieve that objective. Funds are not required to list specific securities in which the fund can invest, but they are required to report the extent to which the fund is permitted to undertake broad activities such as borrowing, lending, and derivatives trading. See Almazan, Brown, Carlson, and Chapman (2004) for a discussion of regulation associated with investment constraints in the context of evaluating fund's choices of investment restrictions.
} 
wealth to the "learning" portfolio, trading off the benefits of more precise information about those stocks' future prospects with the resulting costs of under-diversification.

Industries are given as an example of a common factor that can convey an information advantage. Firms within an industry are likely to have relatively homogeneous production and cost functions, which increases the returns to learning about the industry because the underlying industry exposure more directly maps into the firm's stock performance (Jin and Jorion, 2006). Evidence that a better understanding of an industry can lead to improved estimates of payoffs for firms within the industry is provided by O'Brien (1990), who shows that investment analysts tend to specialize in one industry, and Dunn and Nathan (2005), who show that analysts that focus on one industry produce better forecasts than analysts focusing on multiple industries.

These rationales for institutions' investment decisions guide us to examine three potential sources of variation in institutions' investments in pure play stocks. First, we expect variation across industries, with institutions investing in industries in which asset managers have customer contracting arrangements subject to a performance benchmark. Sector funds and funds with performance benchmarks will arise endogenously in industries in which specialized learning is optimal. Second, we expect variation across time. The pressure to beat benchmarks is likely to be strongest in industries with positive momentum. In addition, investors are more likely to exploit the information advantage gained from specialized learning following favorable information. Third, we expect variation across institution type. Institutions can vary in the degree to which their customer contracts contain performance benchmarks. One might expect mutual fund managers, particularly industry sector funds, to have the strongest benchmark-beating incentives. However, if other institution types have greater information processing capacity (i.e., are less constrained), the learning models would predict that these institutions will engage in specialized information 
acquisition about common risk factors and allocate more wealth to the "learning" portfolio. Ultimately, the association between institution type and investments in pure play stocks will depend on the relationship between resources allocated to learning and the use of performance benchmarking in contracting arrangements, and the possible correlation between the two forces.

\section{Measuring industry exposure}

For the various analyses in this paper, we measure the industry exposure of the stock of each firm $i$ at an annual frequency. Following Tufano (1998), we use daily returns data between January $1^{\text {st }}$ and December $31^{\text {st }}$ each year $y$ to estimate a two factor Dimson (1979) model:

$$
r_{i, t}=\alpha_{i}+\sum_{k=-1}^{k=1} \beta_{i, k}^{m k t} r_{m k t, t+k}+\sum_{k=-1}^{k=1} \beta_{i, k}^{i n d} r_{i n d, t+k}+\varepsilon_{i, t}
$$

where $r_{m k t}$ denotes the daily return on the CRSP equally-weighted market index, and $r_{\text {ind }}$ denotes the daily return on the appropriate equally-weighted industry portfolio. Industry exposure for firm $i$ in year $y$ is:

$$
\beta_{i y}^{\text {ind }}=\beta_{i, 0}^{\text {ind }}+\frac{1+\rho_{1}+\rho_{2}}{1+2 \rho_{1}}\left(\beta_{i, y-1}^{\text {ind }}+\beta_{i, y+1}^{\text {ind }}\right)
$$

where $\rho_{1}$ and $\rho_{2}$ are the autocorrelation coefficients of $r_{\text {ind }}$ during the same year. We require at least 60 daily return observations during year $y$ to estimate industry exposure for a stock. Firms are assigned to one of the Fama-French 30 industry categories using the definitions provided on Kenneth French's website. ${ }^{8}$ We consider alternative measures of industry exposure in sensitivity analysis described in Section 4.3, including the use of a value-weighted index in eqn. (1). We

\footnotetext{
${ }^{8}$ The $30^{\text {th }}$ industry includes firms that do not fall into industries 1 to 29 ; we discard the small number of firms assigned to the $30^{\text {th }}$ industry. We thank Kenneth French for making these data available on his website: (http://mba.tuck.dartmouth.edu/pages/faculty/ken.french/data_library.html).
} 
present results based on using equally-weighted returns to ensure that the returns from a small number of large companies do not overly influence our measure of industry returns, thereby creating a potential mechanical association between firm size and the industry beta. ${ }^{9}$

The estimated coefficients, $\beta_{i y}^{\text {ind }}$, provide a continuous measure of firm $i$ 's industry exposure in year $y$. Table 1 reports descriptive statistics for $\beta^{\text {ind }}$ by industry. The average industry exposure ranges from 0.52 for the Electrical Equipment industry to 0.93 for the Utilities industry (column 1). Intra-industry standard deviations of $\beta^{\text {ind }}$ range from 0.70 to 2.01 (column 2). These patterns suggest we have sufficient intra-industry variation in industry exposure to detect investor preferences for pure play stocks.

We also create two indicator variables to identify high and low exposure firms within each industry. BETAHIGH $H_{i y}$ equals one $\left(B E T A L O W_{i y}\right.$ equals one) if $\beta_{i y}^{\text {ind }}$ is above (below) the $70^{\text {th }}\left(30^{\text {th }}\right)$ percentile industry exposure for stock $i$ 's industry in year $y .{ }^{10}$ The within-industry measurement of the variables controls for the possibility that investors are attracted to particular industries with high average exposures and not to within-industry exposure. The indicator variables also allow us to observe non-linearities in the relation between institutional ownership and a stock's industry exposure. We identify high and low exposure firms (BETAHIGH and BETALOW) before requiring that the sample firms have non-missing COMPUSTAT data that are necessary in the subsequent analysis, thus reducing potential selection bias. The resulting sample contains approximately 2,600 firm-year observations in each of the 23 years from 1984 through 2006.

\footnotetext{
${ }^{9}$ The correlation between firm size measured by market capitalization and industry exposure in the full panel is $10 \%$. The mean log market capitalization is 5.33 for high exposure observations (upper $30 \%$ ) compared to 4.75 for low exposure observations (bottom 30\%).

${ }^{10}$ Henceforth, we drop the subscripts $i$ and $y$ from $\beta^{\text {ind }}$.
} 
We provide out-of-sample evidence that $\beta^{\text {ind }}$, which is based on historical data, predicts future exposure, which is the variable of interest for investors making portfolio allocation decisions. At the start of year $y+1$, we form an equally-weighted hedge portfolio for each industry that goes long stocks classified as high exposure as of December 31 year $y(B E T A H I G H=1)$ and shorts stocks classified as low exposure $(B E T A L O W=1)$ as of December 31 year $y$. The portfolios are rebalanced annually. We regress the returns from the portfolio on the excess returns from the market portfolio and the relevant industry portfolio:

$$
r_{\text {highexp }}-r_{\text {lowexp }}=\alpha+\delta_{m}\left(r_{m k t}-r_{f}\right)+\delta_{\text {ind }}\left(r_{\text {ind }}-r_{f}\right)+\varepsilon
$$

If $\beta^{\text {ind }}, B E T A H I G H$, and BETALOW capture meaningful differences in industry exposure, then we expect to observe $\delta_{\text {ind }}>0$. Table 1 column 3 shows that $\delta_{\text {ind }}>0$ for all industries other than Electrical equipment, Wholesale, and Books.

\section{Empirical analysis of institutions' investments in pure play stocks}

We characterize investor preferences using two approaches. In the first, the unit of observation is a firm-year. We examine the relation between industry exposure and the number of institutions that hold a firm's stock ("institutional ownership" tests). In the second, the unit of analysis is an institution-year. We examine the extent of portfolio tilting toward pure play stocks ("portfolio tilting" tests).

\subsection{Model specifications}

For the institutional ownership tests, we use the following model to estimate the association between institutional ownership and industry exposure: 


$$
\operatorname{LNUMINST}_{i y}=\alpha+\lambda\left(\beta_{i y}^{\text {ind }}\right)+\sum_{k} \delta_{k} \text { CONTROL }_{k i y}+\varepsilon_{i y,}
$$

where $L N U M I N S T_{i y}$ is equal to the natural logarithm of one plus the number of institutions investing in firm $i$ in year $y$. The coefficient central to the analysis is $\lambda$. A significant positive (negative) coefficient reflects attraction (aversion) to a stock's industry exposure $\left(\beta^{\text {ind }}\right)$. We determine the count of institutions that hold a firm's stock by aggregating data from the Thomson Financial 13F database at the end of December each year. We assume that firms that are not included in the reported holdings of any institutions on the Thomson Financial database have zero institutional investors. ${ }^{11}$ We estimate eqn. (3) annually for each year between 1984 and 2006. Standard errors in the annual regressions are clustered by industry.

The model includes a total of 15 control variables (CONTROL). Appendix A provides a detailed description of the measurement of each and Appendix B, Table B1 provides summary statistics. We include 13 firm-specific control variables found to be significant in four influential studies (Del Guercio, 1996; Falkenstein, 1996; Gompers and Metrick, 2001; and Hong and Kacperczyk, 2009). These control variables include firm size, market-to-book ratio, dividend yield, debt-to-equity ratio, the inverse of price, share turnover, price impact as a measure of liquidity, stock market beta, past return volatility, past average firm return, firm age, inclusion of the firm in the S\&P 500 index, and whether the firm is listed on Nasdaq. The firm-specific control variables except firm age are measured with a one-year lag. Firm age and the two index indicator variables are measured contemporaneously. Including the control variables mitigates concerns that an observed association between $\beta^{\text {ind }}$ and institutional ownership can be attributed to a

\footnotetext{
${ }^{11}$ Institutions are required to report holdings in any equity security traded on an exchange including the Nasdaq in a quarterly $13 \mathrm{~F}$ filing. The only exceptions are that holdings under $\$ 20,000$ may be excluded and that institutions that exercise investment discretion over less than $\$ 100$ million in equity are not required to file a Form $13 \mathrm{~F}$.
} 
correlation between industry exposure and a broad asset class, such as small or large cap, value or growth, on which institutions are known to base portfolio allocation decisions (Barberis and Shleifer, 2003).

The model also includes two proxies for investors' expectations about the future prospects of an industry. The first proxy is annual industry returns over the 12 months prior to each year end (January through December) based on the well-documented phenomenon of industry momentum (Moskowitz and Grinblatt, 1999). The second proxy for investors' expectations about future prospects is annual industry returns over the following calendar year, which assumes perfect foresight.

For the portfolio tilting tests, we measure whether institutional investors tilt their portfolios toward pure play stocks by comparing the percentage of an institution's holdings to the weight implied by a value-weighted investment strategy within an industry that reflects no preference for industry exposure (Coval and Moskowitz, 1999). For each institution $j$, we compute the weight of its holdings in stocks of each exposure type $e$ (i.e., high, medium or low) within each industry $i$ for each year $y$ :

$$
P H E L D_{i j y}^{e}=\sum_{s=1}^{S} M V_{i j y}^{s} / \sum_{f=1}^{F} M V_{i j y}^{f}
$$

The numerator is the market value of institution $j$ 's holdings of stocks in industry $i$ with exposure level $e$ in year $y$, where $S$ is the number of stocks in industry $i$ of type $e$ within the institution's portfolio. The denominator is the market value of institution $j$ 's total holdings of stocks in industry $i$ in year $y$, where $F$ is the number of stocks in industry $i$ within the institution's portfolio. We compute the weight for each institution at the end of December for each year between 1984 and 2006. 
We compute the benchmark weight $(w)$ for each industry $i$ in each year $y$ as the valueweighted percentage of stocks classified as having high, medium, or low industry exposure $(e)$ :

$$
w_{i y}^{e}=\sum_{g=1}^{G} M V_{i y}^{g} / \sum_{n=1}^{N} M V_{i y}^{n}
$$

where $G$ is the number of firms in industry $i$ in year $y$ with industry exposure level $e$, and $N$ is the total number of firms in industry $i$ in year $y$. The excess weight in each exposure category (XSBETA) equals the percentage held in each exposure category minus the benchmark weight:

$$
X \mathrm{SBETA}_{i j y}^{e}=P H E L D_{i j y}^{e}-w_{i y}^{e} .
$$

XSBETA measures whether, conditional on investing in a particular industry, an institutional investor overweights or underweights stocks with industry exposure level $e$ relative to a simple strategy of investing in a value-weighted industry index.

The excess weights across the three industry exposure categories (i.e., high, medium, and low) for each institution-industry-year observation sum to zero. We expect that institutional investors that show preferences for pure play stocks will overweight high exposure stocks $\left(X_{S B E T A_{i f y}^{e}}^{e}>0\right)$. The null hypothesis that institutions do not overweight (underweight) high (low) exposure stocks is $X S B E T A_{i j y}^{e}=0$.

\subsection{Empirical results}

Table 2 Panel A presents the institutional ownership tests. We report the average of the annual coefficient estimates from eqn. (3). Significance levels are based on a test statistic 
computed from the annual $t$-statistics that considers serial correlation. ${ }^{12}$ The coefficient estimates for the control variables are consistent with prior research. The number of institutional investors holding a stock is positively associated with firm size, the inverse of price, share turnover, stock market beta, past firm and industry returns, firm age, and inclusion in the S\&P 500 index, and negatively associated with the market-to-book ratio, dividend yield, debt-to-equity ratio, price impact, and listing on Nasdaq.

Our main finding is a positive and statistically significant association between industry exposure and the number of institutions holding a firm's stock after controlling for other firm characteristics. A stock with no industry exposure would experience $23 \%$ fewer institutional investors than a stock with an industry exposure of one, ceteris paribus (column 1). Using the indicator variables BETAHIGH and BETALOW to measure industry exposure, the coefficient estimates indicate that the positive association between $\beta^{\text {ind }}$ and the number of institutional investors comes from both investments in pure play stocks and aversions to low exposure stocks relative to firms with medium levels of industry exposure. A change in a firm's industry exposure from the $30^{\text {th }}$ percentile (low exposure stock) to the $70^{\text {th }}$ percentile (high exposure stock) is associated with a $35 \%$ increase in the number of institutional owners.

Panel B presents the portfolio tilting results. The average annual value of $X S \_B E T A H I G H$ is 0.0138 , which indicates that institutions overweight high exposure stocks by 138 bps relative to

\footnotetext{
${ }^{12} Z=\bar{t} \sqrt{(N-1)} / \sigma(t)$ where $t_{j}$ is the $t$-statistic for year $j, N$ is the number of years, and $\bar{t}$ and $\sigma(t)$ are the mean and standard deviation, respectively, of the $N$ realizations of $t_{j}$. $Z$ has a $t$ distribution with $N-1$ degrees of freedom.
} 
their weights in a value-weighted industry portfolio. Institutions underweight low-exposure stocks by 142 bps. The over and underweighting are both significantly different from zero. ${ }^{13}$

\subsection{Robustness tests}

Table 3 reports sensitivity analysis of the results to several alternative measures of industry exposure. For ease of comparison, column (1) repeats the results from Table 2. Panel A reports results using the alternative continuous measures of industry exposure and Panel B reports results using their indicator variable counterparts. All models include the control variables. The estimated coefficients for the control variables are consistent with the results in Table 2 in terms of sign, magnitude, and significance and are not reported.

The first alternative measure is the absolute value of industry exposure. The coefficient estimate on the absolute value of $\beta^{\text {ind }}$ is positive and statistically significant and the results for BETAHIGH and BETALOW also are robust to this alternative measure of industry exposure. ${ }^{14}$

In columns 3 through 5 we report coefficient estimates on the exposure proxies from models using three alternative measures of $\beta^{\text {ind }}$, all of which are derived from estimation of augmented versions of eqn. (1). The model adjustments are: a) including the Fama-French (1993) factors (SMB and HML); b) using value-weighted market and industry returns instead of equallyweighted market and industry returns; and c) using monthly data over a five-year period rather

\footnotetext{
${ }^{13}$ Results for the full sample in Panels A and B are not sensitive to the exclusion of stocks classified in the financial services industry.

${ }^{14}$ This finding sheds light on the rationales for preferences for pure play stocks. Incentives to beat performance benchmarks suggest stronger preferences for high positive exposure stocks because many funds have constraints on short positions. In contrast, learning models suggest greater preferences for either extreme positive or negative exposure because signal precision is increased in both cases. The magnitude of the coefficient estimate on $\left|\beta^{\text {ind }}\right|$ in column (2) is smaller than the coefficient on $\beta^{\text {ind }}$ in column (1), consistent with contracting arrangements, in particular constraints on short positions, dampening preferences for negative exposure stocks. To further explore this possibility, we restricted the sample to those stocks with negative industry exposures $(\mathrm{n}=577)$. In this sub-sample, the association between LNUMINST and $\left|\beta^{\text {ind }}\right|$ is negative and significant (untabulated).
} 
than daily data over a one-year period. The results using the alternative measures are qualitatively similar to those presented in Table $2 .^{15}$

The next set of robustness tests estimates exposure preferences within characteristic-sorted portfolios of firms. The analysis is intended to address concerns about omitted correlated variables. We regress institutional ownership on exposure within portfolios sorted based on proxies for firm-specific risk (Panel A), financial reporting transparency (Panel B), liquidity (Panel C), and firm size (Panel D). ${ }^{16}$ These four firm characteristics are potentially correlated with both industry exposure $\left(\beta^{\text {ind }}\right)$ and institutional investments. If the results hold within the portfolios of firms with similar levels of the characteristic, then correlations between exposure and these four characteristics do not fully explain our results.

Panel A reports the coefficient estimates from the model of the number of institutions holding a stock [eqn. (3)] within portfolios sorted based on firm-specific risk (FIRMRISK). We measure FIRMRISK as the standard deviation of the residuals from the extended market model in eqn. (1) that controls for both market and industry risk. Firms in the bottom (middle two) \{upper quartile in year $y$ are in the low (middle) $\{$ high $\}$ FIRMRISK portfolio. ${ }^{17}$ Coefficient estimates for the control variables are not tabulated. Industry exposure $\left(\beta^{\text {ind }}\right)$ remains positively associated with the number of institutional investors within all three FIRMRISK portfolios (column 1). The results using the indicator variables $B E T A H I G H$ and $B E T A L O W$ show that high industry-exposure stocks

\footnotetext{
${ }^{15}$ Appendix $\mathrm{C}$ and Table $\mathrm{C} 1$ describe a set of additional alternative specifications using seven macro-economic risk factors.

${ }^{16}$ The models presented in Table 2 provide controls for the main effects of three of the four characteristics: risk as measured by return volatility (RETVOL), liquidity as measured by price impact (PRICEIMPACT), and firm size as measured by the natural logarithm of the market value of equity ( $\left.L O G S I Z E_{-} M V E\right)$. In results not reported, we also add the variable FIRMRISK to the models in Table 2. The coefficient on FIRMRISK is negative and significant, but the coefficient on industry exposure does not change.

17 The estimated coefficients for the control variables are consistent with the results in Table 2 in terms of sign, magnitude, and significance and are not reported.
} 
experience more institutional investors than low industry-exposure stocks across all three FIRMRISK portfolios. The association, however, is lower in magnitude and less frequently significant in the annual regressions for firms in the upper quartile of firm risk. Given that FIRMRISK is negatively correlated with firm size, one possible explanation for the dampened results in the high FIRMRISK portfolio is that institutions invest in small firms because of their size and not their industry exposure. Consistent with this explanation, the 16 years that are significant are primarily in the later part of the sample period when institutional investors shifted their investments toward smaller firms (Blume and Keim, 2014). ${ }^{18}$ We consider the potential effect of size on our inferences in Panel D, discussed below.

Table 4 Panel B reports the coefficient estimates from eqn. (3) within portfolios sorted based on financial reporting transparency. This analysis is motivated by concerns that single segment firms, which are more likely to have high industry exposure, also have greater financial reporting transparency, which investors value. ${ }^{19}$ We sort firms into quartiles based on line-ofbusiness diversification as a proxy for financial reporting transparency. Line-of-business diversification (DIVERSIFICATION) is measured as one minus the firm's revenue-based concentration ratio, as defined in Appendix A. The minimum value of DIVERSIFICATION is zero for a single-segment firm, which is presumed to be the most transparent. The value approaches one as diversification increases (i.e., financial reporting transparency decreases). Firms in the bottom (middle two) \{upper $\}$ quartile in year $y$ are in the low (middle) $\{$ high $\}$ DIVERSIFICATION

\footnotetext{
${ }^{18}$ The correlation between FIRMRISK and size is $-52 \%$ in the full panel. The highest (lowest) correlation is $-65.6 \%$ in 1992 (-41.5\% in 1999). The 16 significant years are 1985, 1990-1992, and 1995-2006.

${ }^{19}$ For evidence on investor attraction to transparency in general, see for example Bartov and Bodnar (1996), Boone and Raman (2001), and Eleswarapu, Thompson, and Venkataraman (2004). For evidence on attraction to transparency by institutional investors in particular, see Healy, Hutton, and Palepu (1999) and Bushee and Noe (2000). For evidence that firms that operate in fewer lines of business, and hence are likely to have greater industry exposure, produce financial statements with greater information precision (i.e., transparency) about firm value, see Baldwin (1984) and Bushman, Chen, Engel, and Smith (2004).
} 
portfolio. Across all three characteristic sorted portfolios, institutions exhibit robust clientele effects for pure play stocks based on both the continuous measure of exposure $\left(\beta^{\text {ind }}\right)$ and the indicator variables BETAHIGH and BETALOW.

Table 4 Panel C reports the coefficient estimates within portfolios sorted based on liquidity. We proxy for the liquidity of a firm's stock using the Amihud (2002) price impact measure (PRICEIMPACT), computed as the average daily price impact of trades during each year $y$ :

$$
\text { PRICEIMPACT }_{i y}=\frac{1}{T} \sum_{t=1}^{T} \frac{\left|r_{i, t}\right|}{V_{i, t}},
$$

where $r_{i, t}$ denotes the returns for firm $i$ on day $t$ excluding dividends and $V o l_{i, t}$ denotes the number of shares of firm $i$ traded on day $t$. Days on which no trades are made are excluded from the calculations. The smaller the price impact, the more liquid is the stock. Following Amihud (2002), we normalize the measure by dividing by the mean value of the Amihud measure across stocks in each year. Some extreme values remain and we winsorize the normalized measure at the $99^{\text {th }}$ percentile.

Firms in the bottom (middle two) \{upper\} quartile of PRICEIMPACT in year $y$ are classified in the high (medium) $\{$ low $\}$ liquidity portfolio. The coefficient estimate for $\beta^{\text {ind }}$ remains positive and statistically significant within the medium and low liquidity-sorted portfolios. The magnitudes are dampened and the number of significant annual estimates is lower than for the full panel. The weaker results could reflect less power because of a smaller number of observations or could reflect a correlation between liquidity and exposure. While the estimates are weaker, industry exposure nonetheless still exhibits a statistically significant incremental impact on institutional ownership for low and medium liquidity stocks. However, in the high-liquidity portfolio, the magnitude of the relation between exposure and institutional ownership is only 
0.0165 (and not statistically different from zero). The results using the indicator variables BETAHIGH and BETALOW also suggest that institutions' investments in pure play stocks are weakest in high-liquidity stocks. The difference between the BETAHIGH and BETALOW coefficient estimates in the high liquidity portfolio (bottom PRICEIMPACT portfolio) is only 0.0252, and the individual annual differences are only significant in seven of the 23 annual model estimations.

The dampened results in the high-liquidity portfolio may again (as in Panel A) suggest that firm size is an omitted correlated variable in the analysis. The high-liquidity stocks are large firms (average market cap of $\$ 7.2$ billion and $39.5 \%$ of the firms are in the S\&P 500), which will be part of most institutional stock portfolios regardless of industry exposure. In the lowest liquidity quartile, firms have an average market capitalization of $\$ 75$ million and less than $0.1 \%$ are in the S\&P 500. In the full panel, the correlation between firm size and PRICEIMPACT is -0.358 (i.e., higher liquidity). Given that LIQUIDITY is positively correlated with firm size, one possible explanation for the dampened results in the high LIQUIDITY portfolio is that institutions invest in large firms because of their size and not their industry exposure. Consistent with this explanation, the seven years that are significant are primarily in the earlier part of the sample period when institutional investors demonstrated preferences for larger firms (Blume and Keim, 2014). ${ }^{20}$

In light of the indications of time-varying size effects in Panels $\mathrm{A}$ and $\mathrm{C}$ that could confound interpretation of the results, we also conduct portfolio sorts based on size even though the main model controls for a linear association between log size and institutional ownership. Table 4 Panel D reports the coefficient estimates within three size portfolios. Firms in the bottom (middle two) \{upper\} quartile of firm size measured by market capitalization are in the small

\footnotetext{
${ }^{20}$ The seven years are 1985, 1988-1989, 1991, 1993-1994, and 2003.
} 
(medium) \{large $\}$ firm portfolio. Across all three firm size portfolios, institutions exhibit preferences for pure play stocks based on both the continuous measure of exposure $\left(\beta^{\text {ind }}\right)$ and the indicator variables BETAHIGH and BETALOW. Untabulated results do not show a time trend in the significance of the coefficient estimates across the size-sorted portfolios.

Taken together, the results in Table 4 suggest that four plausible omitted correlated variables are not driving our results. The results in Panels A, C, and D, do however suggest that institutions exhibit size preferences although these preferences do not fully explain our results. To further alleviate concerns about firm size effects, we estimate the main model using a cubic specification of firm size (untabulated) based on the findings of Blume and Keim (2014). Our main finding that institutions invest in pure play stocks remains. ${ }^{21}$ We also estimate our main regression within portfolios of small cap, mid-cap, large cap, and mega cap firms as defined in Blume and Keim (2014). Our results are robust across all four size-based portfolios.

\section{Evidence on liquidity in pure play stocks}

As noted in the introduction, the salient factor in a firm's risk management decision is not institutional ownership per se but the economic benefit that the institutional ownership provides. A common characterization is that institutions primarily provide either monitoring or trading/liquidity benefits (e.g., Chen, Harford, and Li, 2007). In this section, we examine measures of liquidity to assess the potential economic magnitude of the benefits to a firm from remaining exposed to the underlying industry factor. We measure liquidity associated with industry exposure in an OLS regression model that controls for determinants identified in prior literature. We use

\footnotetext{
${ }^{21}$ The coefficient estimate on $\beta^{\text {ind }}$, the continuous measure of exposure, in this specification is 0.23 . The difference between the coefficient estimates on the BETAHIGH and BETALOW binary variables is 0.35 .
} 
two proxies for liquidity. Share turnover $(T U R N O V E R)$ is the natural logarithm of average monthly turnover (volume divided by shares outstanding), computed for each firm $i$ in each year y. We also use the Amihud (2002) price impact measure (PRICEIMPACT), defined previously, given criticisms of turnover and spread measures of liquidity (Goyenko, Holden, and Trzcinka, 2009). The model includes all of the control variables included in eqn. (3) with the exception of TURNOVER and PRICEIMPACT.

Table 5 reports the results. Column (1) shows a strong positive association between industry exposure and turnover. Ceteris paribus, turnover in firms with high industry exposure is $45 \%$ higher than in firms with medium levels of exposure, while turnover in low exposure firms is $29 \%$ lower than for medium exposure firms. These results are not changed when we measure industry exposure using BETAHIGH and BETALOW in column 2. ${ }^{22}$ Using the natural logarithm of Amihud's measure of price impact as a proxy for liquidity produces similar results in columns 3 and 4. Price impact is significantly and negatively related to industry exposure. The price impact for firms with high exposure is $47 \%$ lower than the price impact for firms with medium exposure, while the price impact for low exposure firms is $60 \%$ greater than the price impact for firms with medium exposure.

\section{Evidence on investments in pure play stocks across time, industries and institution types}

In this section, we characterize variation in institutions' investments in pure play stocks across time (Section 6.1), industry (Section 6.2), and institution type (Section 6.3).

\footnotetext{
${ }^{22}$ The turnover results are not sensitive to excluding Nasdaq firms.
} 


\subsection{Time variation}

In Table 6, we condition the preferences for industry exposure on the favorableness of recent industry news. As noted in Section 2, we expect the pressure to beat a benchmark and to invest based on acquired information are greater when the stock has positive momentum. In column (1), we augment the model of institutional ownership to include interaction terms between the continuous industry exposure measure $\left(\beta^{\text {ind }}\right)$ and indicator variables that denote if past industry returns are high (HIGHPASTIND) or low (LOWPASTIND), defined as above (below) the $75^{\text {th }}\left(25^{\text {th }}\right)$ percentile of annual returns within the industry. The models include all of the control variables, but we only tabulate the coefficient estimates for the main effect of PASTINDRET. During periods with favorable news about an industry, institutions' investments in pure play stocks are significantly more pronounced than those during periods with neutral news about an industry (annual returns in the $25^{\text {th }}-75^{\text {th }}$ percentiles). The reverse is true during periods of unfavorable news.

In column (2) the interaction terms are the products of the indicator variables for industry exposure (BETAHIGH and BETALOW) and the continuous measure of past industry returns (PASTINDRET). After controlling for the main effect of past industry returns, the coefficient on the interaction of BETALOW with past industry returns is significantly negative, while the coefficient on the interaction of BETAHIGH with PASTINDRET is significantly positive. Similar to the inferences from column (1), investments in pure play stocks and aversion to low exposure stocks are amplified following favorable news.

In Panel B, we report the results of the institution-level tests of portfolio tilting conditioning on past industry returns. During years of favorable past performance, institutions overweight pure play stocks by 258 bps compared to 157 bps in industries with low past returns. 


\subsection{Industry variation}

We examine institutions' investments in pure play stocks across industries characterized based on homogeneity. Industry homogeneity is measured as the average annual difference between the adjusted $\mathrm{R}^{2}$ values of two models for each industry-year: a standard market model and the extended market model in eqn. (1), each estimated using panel daily return data for the firms in industry $i$ during calendar year $y$. The greater the average difference in adjusted $\mathrm{R}^{2} \mathrm{~s}$, the greater is the industry homogeneity (HOMOGENEITY). ${ }^{23}$

Figure 1 presents box plots of the industry homogeneity metric over our sample period from 1984 through 2006 for each of the 30 Fama-French industries. Five industries stand out as having substantially higher industry homogeneity: coal, tobacco, utilities, mining, and crude oil and natural gas. We designate these five industries as high homogeneity industries. For the high homogeneity industries, on average, the adjusted $\mathrm{R}^{2}$ in the extended market model is $12 \%$ higher in absolute terms than the adjusted $\mathrm{R}^{2}$ in the standard market model. We designate the five industries with the lowest average homogeneity as low homogeneity industries: wholesale, services, games, fabricated products, and electrical equipment. ${ }^{24}$ The adjusted $\mathrm{R}^{2}$ for the low homogeneity industries increases by just $0.6 \%$ in absolute terms. The remaining industries are classified as medium-homogeneity. ${ }^{25}$

\footnotetext{
${ }^{23} \mathrm{We}$ also measure industry homogeneity as the incremental power of the industry factor relative to the market factor (F-statistic). The measures based on both methods are highly correlated and our results are similar with both measures. ${ }^{24} \mathrm{We}$ include five industries in the low homogeneity sample to match the number of industries that stand out as high homogeneity industries.

${ }^{25}$ Our classification of industries as high, medium, or low homogeneity does not change over the sample period. Figure 1 illustrates variation in homogeneity during the sample period for many industries, however, much of this variation is due to an increasing trend in industry homogeneity from 1984 through 2006 across all industries. The relative ranking of the industries remains stable throughout the sample period. The only exception is the homogeneity measure for the coal industry, which has a small number of firms. All results are robust to exclusion of the coal industry observations from the regressions.
} 
We expect institutions' preferences to be more pronounced in more homogeneous industries for two reasons. First, these industries are the most common targets of sector funds, ${ }^{26}$ and sector funds are the most likely to have an industry-based performance benchmark. Second, institutions are more likely to attempt to acquire an information advantage in these industries by learning about the common industry risk factor because the underlying industry exposure more easily maps into the firm's stock performance (Jin and Jorion, 2006).

Table 7 presents the results conditioning on industry homogeneity. On average, institutions' investments in pure play stocks are increasing in industry homogeneity (Panel A). Based on estimates for our continuous measure of industry exposure, a stock with zero industry exposure in a high homogeneity industry will have $28 \%$ fewer institutional investors than a stock with industry exposure equal to one, ceteris paribus. In contrast, the difference is only $18 \%$ for stocks in low homogeneity industries. Using the indicator variables for high and low industryexposure we find that in high and medium-homogeneity industries, a change in a firm's industry exposure from the $30^{\text {th }}$ percentile to the $70^{\text {th }}$ percentile is associated with a $36 \%$ increase in the number of institutions holding the stock, compared to just $23 \%$ in low homogeneity industries.

The portfolio tilting tests provide even more pronounced evidence that preferences for exposure increase with industry homogeneity (Table 7 Panel B). Institutions overweight pure play stocks in high homogeneity industries by 388 bps and underweight low-exposure stocks by 601 bps. In medium-homogeneity industries the overweightings (underweightings) are less pronounced at $139 \mathrm{bps}$ (105 bps), and in low homogeneity industries, institutions do not significantly overweight (underweight) high- (low-) exposure stocks.

\footnotetext{
${ }^{26}$ The industries that we designate as high homogeneity also are the industries in which Exchange-Traded Funds (ETFs) are concentrated (Lipper, 2005).
} 


\subsection{Institutional type variation}

We classify institutional investors in two ways. First, we use the classification system in the Thomson Financial database based on 13F filings, which is used in numerous prior studies of institutional ownership: (1) bank trusts, (2) insurance companies, (3) investment companies, (4) investment advisors, and (5) other. The "other" category includes pension and endowment funds. ${ }^{27}$ We aggregate the investment companies and investment advisors into one institution type. ${ }^{28}$ Second, we use the Bushee (1998) classifications of institutional investors based on observed trading activity. Bushee (1998) identifies three types of institutional investors: Dedicated owners, quasi-indexers, and transient investors. ${ }^{29}$ Dedicated owners have large, long-term holdings, concentrated in a small number of firms, and are more likely to gather private information about a firm and directly monitor its managers. Quasi-indexers tend not to rely heavily on private information and adopt a passive monitoring style. Transient investors hold small stakes in many firms and trade frequently on publicly available information, but they do not generally acquire private information.

Table 8 reports results for institutional groupings based on $13 \mathrm{~F}$ filings. All models of institutional ownership include the same set of control variables as in the previous analyses; results

\footnotetext{
${ }^{27}$ Thomson Financial reports that there is a coding error in the 13F database. Partway through 1998, and in subsequent years, many banks (Type 1) and independent investment advisors (Type 4) are misclassified as other institutions (Type 5). Bushee's data at http://acct.wharton.upenn.edu/faculty/bushee/IIclass.html provides a consistent classification of the institutions.

${ }^{28}$ We combine the investment companies and investment advisors because Thomson Financial indicates that the Investment Company category (Type 3) includes investment advisors for which a "significant" portion of their advisory services are to the mutual fund business.

${ }^{29}$ The Bushee (1998) annual institution classifications are based on k-means clustering of standardized factor scores, which are created on an institution-year basis using the weighted average of firm-specific characteristics of an institution's portfolio holdings. Approximately $4 \%$ of institution-year observations are dedicated owners, $60 \%$ are quasi-indexers, and $36 \%$ are transient investors.
} 
for the control variables are consistent with those reported in terms of magnitude, sign and significance, and are not tabulated. Panel A shows that all types of institutions display a significant attraction to high industry exposure stocks and a significant aversion to low exposure stocks. The association between institutional ownership and pure play stocks is strongest for investment advisors using both the continuous exposure measure and the indicator variables (columns 3 and 7).

Panel B reports institutional ownership results across the high and low homogeneity industries. In both groups, all institution types exhibit significant preferences for industry exposure, with uniformly stronger preferences for stocks in high homogeneity industries. Panel C reports the portfolio tilting results. All institutions other than banks tilt toward high exposure stocks and away from low exposure stocks. As in the institutional ownership tests in Panel B, the preferences for industry exposure are uniformly stronger in high homogeneity industries. Only investment advisors exhibit preferences for pure play stocks in low homogeneity industries. The banks are an exception, possibly because of their fiduciary status under the prudent man standard and the prudent investor rule (Del Guercio, 1996; Hankins, Flannery, and Nimalendran, 2008).

Table 9 reports results for institutional groupings based on observed trading activity (Bushee, 1998). All three categories show a positive association between institutional investors and exposure, and the association is driven by both an aversion to low industry exposure stocks and an attraction to high exposure stocks (Panel A). Using both the continuous measure of exposure (columns 1 - 3) and the indicator variables (columns 4 - 6), the investments in pure play stocks are strongest for transient investors followed by quasi-indexers and dedicated owners.

The averaging of the annual coefficient estimates across the 1984 to 2006 sample period obscures a time trend in the significance of the BETAHIGH coefficient estimate for transient 
investors and quasi-indexers. The coefficients are not statistically different from zero in the 1980's and early 1990's, but they are consistently significantly positive in the last ten years of the sample period. This increased investment in pure play stocks by transient investors coincides with the introduction and rapid growth of Exchange Traded Funds (ETFs). In 1993 the first ETF was traded on the American Stock Exchange (AMEX). The number of funds grew from one in 1993 to 359 by the end of 2006, and the assets invested in ETFs grew from approximately $\$ 1$ billion to $\$ 422$ billion..$^{30}$ ETFs are designed to track returns in particular sectors or markets, providing investors with access to sector or market exposure at a lower cost than more traditional mutual funds. A cost effective way for ETFs to track returns in a particular sector, such as utilities, is to invest in the stocks of firms that have high industry exposure. ETFs typically hold a large number of stocks, so they are likely to be classified as either transient or quasi-index investors. The rapid growth in ETFs may, at least in part, explain the increased investment in pure play stocks among transient and quasi-index investors over the last decade.

Table 9 Panel B reports the results for institutional groupings across high and low homogeneity industries. In high homogeneity industries, all institutions invest in pure play stocks and avoid low industry exposure stocks. Similar to the patterns in investment across institutions observed in Panel A, preferences in the high homogeneity industries are strongest for transient investors followed by quasi-indexers and dedicated owners. In low homogeneity industries, there is limited evidence of aversion to low exposure stocks and no evidence of preferences for high exposure stocks. Portfolio titling tests in Panel $\mathrm{C}$ show that both dedicated owners and transient investors overweight (underweight) pure play (low exposure) stocks in the sample of all industries. The excess weightings, however, are only economically meaningful for the transient investors.

\footnotetext{
${ }^{30}$ The source of the annual statistics is the Investment Company Institute (ICI) Fact Book, 2008.
} 
Moreover, the transient investors' excess weightings are strongest in the high homogeneity industries relative to the low homogeneity industries. Dedicated owners overweight high exposure stocks, regardless of industry.

\section{Conclusion}

We document that institutions exhibit preferences for pure play stocks, defined as stocks with high exposure to the firm's industry factor. The number of institutional investors holding a firm's stock is increasing in a firm's level of industry exposure and institutional investors overweight (underweight) high (low) industry-exposure stocks in their portfolios. Institutional investments in pure play stocks are more pronounced during times of favorable industry news and in homogeneous industries that have greater intra-industry exposure to a common factor. Preferences for pure play stocks are reflected in investment choices by all types of institutions, but they are concentrated in institutions generally considered to be liquidity providers. Consistent with this concentration, we observe greater liquidity in pure play stocks as measured by share turnover and price impact.

Documenting these patterns is a first step in the process of studying whether and when firms might adjust their risk management practices to cater to investor preferences. Our evidence broadly suggests that a firm's hedging decision should weigh the potential liquidity benefits gained by not hedging against the benefits of variability reduction, which conventional models attribute to hedging. Our cross-sectional evidence on when and where the potential liquidty benefits are expected to be strongest is important to guide future work that attempts to explain firms' risk management decisions. 


\section{References}

Acharya, V., \& Pedersen, L. (2005). Asset pricing with liquidity risk. Journal of Financial Economics, 77, 375-410.

Allayannis, G. \& Weston, J. (2001). The use of foreign currency derivatives and firm value, Review of Financial Studies, 14, 243-276.

Almazan, A., Brown, K., Carlson, M., \& Chapman, D. (2004). Why constrain your mutual fund manager? Journal of Financial Economics, 73, 289-321.

Amihud, Y. (2002). Illiquidity and stock returns: Cross-section and time-series effects. Journal of Financial Markets, 5, 31-56.

Baker, M., \& Wurgler, J. (2004). A catering theory of dividends. Journal of Finance, 59, 11251165.

Baldwin, B. A. (1984). Segment earnings disclosure and the ability of security analysts to forecast earnings per share. The Accounting Review, 59, 376-389.

Barberis, N., \& Shleifer, A. (2003). Style investing. Journal of Financial Economics, 68, 161-199.

Bartov, E., \& Bodnar, G. M. (1996). Alternative accounting methods, information asymmetry and liquidity: Theory and evidence. The Accounting Review, 71, 397-418.

Bennett, J. A., Sias, R. W., \& Starks, L. T. (2003). Greener pastures and the impact of dynamic institutional preferences. Review of Financial Studies, 16, 1203-1238.

Berk, J., \& DeMarzo, P. (2014). Corporate Finance, Prentice Hall.

Blume, M., \& Keim, D. (2014). The changing nature of institutional stock investing, Critical Finance Review 7, forthcoming.

Boone, J. P., \& Raman, K. K. (2001). Off-balance sheet R\&D assets and market liquidity. Journal of Accounting and Public Policy, 20, 97-128.

Brealey, R., S. Myers, \& Allen, F. (2014). Principles of Corporate Finance, McGraw-Hill.

Bushee, B. (1998). The influence of institutional investors on myopic R\&D investment behavior. The Accounting Review, 73, 305-333.

Bushee, B. (2011). http://acct3.wharton.upenn.edu/faculty/bushee/IIclass.html.

Bushee, B. J., \& Noe, C. F. (2000). Corporate disclosure practices, institutional investors, and stock return volatility. Journal of Accounting Research, 38, 171-202.

Bushman, R., Chen, Q., Engel, E., \& Smith, A. (2004). Financial accounting information, organizational complexity and corporate governance systems. Journal of Accounting and Economics, 37, 167-201.

Chan, J. S. P. (2002). Persistence, Uncertain Liquidity, and Expected Return. Working Paper, UCLA.

Chen, X., Harford, J., \& Li, K. (2007). Monitoring: Which institutions matter? Journal of Financial Economics, 86, 279-305. 
Comment, R., \& Jarrell, G. A. (1995). Corporate focus and stock returns. Journal of Financial Economics, 37, 67-87.

Coval, J., \& Moskowitz, T. (1999). Home bias at home: Local equity preference in domestic equity portfolios. Journal of Finance, 54, 2054-2073.

Chordia, T. A. Subrahmanyam, A. and R. Anshuman (2001). Trading activity and expected returns. Journal of Financial Economics, 59, 3-32.

Del Guercio, D., 1996. The distorting effect of the prudent man law of institutional equity investments. Journal of Financial Economics, 40, 31-62.

Dimson, Ely, 1979, Risk measurement when shares are subject to infrequent trading, Journal of Finance Economics, 7, 197-226.

Doidge, C., Karolyi, G. A., \& Stulz, R. M. (2004). Why are foreign firms listed in the US worth more? Journal of Financial Economics, 71, 205-238.

Dunn, K., \& Nathan, S. (2005). Analyst industry diversification and earnings forecast accuracy. Journal of Investing, 14, 7-14.

Eleswarapu, V. R., Thompson, R. W., \& Venkataraman, K. (2004). The impact of Regulation Fair Disclosure: Trading costs and information asymmetry. Journal of Financial and Quantitative Analysis, 39, 209-225.

Falkenstein, E. (1996). Preferences for stock characteristics as revealed by mutual fund portfolio holdings. Journal of Finance, 51, 111-135.

Fama, E., \& French, K. (1993). Common risk factors on the returns of stocks and bonds. Journal of Financial Economics, 33, 3-56.

Froot, K., Scharfstein, D., \& Stein, J. (1993). Risk management: Coordinating corporate investment and financing policies. Journal of Finance, 48, 1629-1658.

Géczy, C., Minton, B.A. \& Schrand, C. (1997). Why firms use currency derivatives. Journal of Finance, 52, 1323-1354.

Gompers, P., \& Metrick, A. (2001). Institutional investors and equity prices. Quarterly Journal of Economics, 118, 229-260.

Goyenko, R., Holden, C. W., \& Trzcinka. C. A. (2009). Do liquidity measures measure liquidity? Journal of Financial Economics, 92, 153-181.

Guay, W. \& Kothari, S. (2003). How much do firms hedge with derivatives? Journal of Financial Economics, 70, 423-461.

Hankins, K. W., Flannery, M. J., \& Nimalendran, M. (2008). The effect of fiduciary standards on institutions' preferences for dividend-paying stocks. Financial Management, winter 2008, 647-671.

Healy, P. M., Hutton, A. P., \& Palepu, K. G. (1999). Stock performance and intermediation changes surrounding sustained increases in disclosure. Contemporary Accounting Research, $16,485-520$. 
Hong, H., \& Kacperczyk, M. (2009). The price of sin: The effects of social norms on markets. Journal of Financial Economics, 93, 15-36.9.

Jin, Y., \& Jorion, P. (2006). Firm value and hedging: Evidence from U.S. oil and gas producers. Journal of Finance, 61, 893-919.

Kacperczyk, M., Sialm, C., \& Zheng, L. (2005). On the industry concentration of actively managed equity mutual funds. Journal of Finance, 60, 1983-2011.

Maug, Ernst, and Narayanan Naik (1996). Herding and Delegated Portfolio Management: The Impact of Relative Performance Evaluation on Asset Allocation. Working Paper.

McEwen, Rob, 2002, In Depth with Rob McEwen, CE, Goldcorp, Interview, Denver (November 10), TIM Wood, Mineweb.

Moskowitz, T. J., \& Grinblatt, M. (1999). Do industries explain momentum? Journal of Finance, 54, 1249-1290.

Nance, D. R., Smith Jr., C. W., \& Smithson, C. W. (1993). On the determinants of corporate hedging. Journal of Finance, 48, 267-284.

O'Brien, P. (1990). Forecast accuracy of individual analysts in nine industries. Journal of Accounting Research, 28, 286-304.

Pastor, L. \& R. Stambaugh (2003). Liquidity risk and expected stock returns. Journal of Political Economy, 111, 642-685.

Peng, L., \& Xiong, W. (2006). Investor attention, overconfidence and category learning. Journal of Financial Economics, 80, 563-602.

Rampini, A., Sufi, A., \& Viswanathan, V. (2014). Dynamic risk management. Journal of Financial Economics, 111, 271-296.

Sensoy, B. (2009). Performance evaluation and self-designated benchmark indexes in the mutual fund industry. Journal of Financial Economics, 92, 25-39.

Sirri, E. R., \& Tufano, P. (1998). Costly search and mutual fund flows. Journal of Finance, 53, 1589-1622.

Smith, C., \& Stulz, R. (1985). The determinants of firms' hedging policies. Journal of Financial and Quantitative Analysis, 20, 391-405.

Stulz, R. (1984). Optimal hedging policies, Journal of Financial and Quantitative Analysis 19, 127-140.

Tufano, P. (1996). Who manages risk? An empirical examination of risk management practices in the gold mining industry. Journal of Finance, 51, 1097-1137.

Tufano, P. (1998). The determinants of stock price exposure: Financial engineering and the gold mining industry. Journal of Finance, 53, 1015-1052.

Van Nieuwerburgh, S., \& Veldkamp, L. (2010). Information acquisition and portfolio underdiversification. Review of Economic Studies, 77, 779-805.

Wang, A. (2003). Institutional Equity Flows, Liquidity Risk and Asset Pricing. Working paper, UCLA. 


\section{Figure 1: Industry homogeneity}

To measure industry homogeneity for industry $j$ in year $y$, we estimate a standard market model and an extended market model that includes an industry factor for each firm $i$ within industry $j$. We use daily return data over the period January to December of year $y$. The extended market model includes the appropriate equally-weighted industry returns and the equally-weighted market returns. For each firm $i$ in year $\mathrm{y}$, we compute the difference between the adjusted $\mathrm{R}^{2}$ values of the two models. We use the average difference in adjusted $\mathrm{R}^{2}$ values within an industry as our measure of industry homogeneity. The box plot below summarizes the industry homogeneity across our sample period of $1984-2006$.

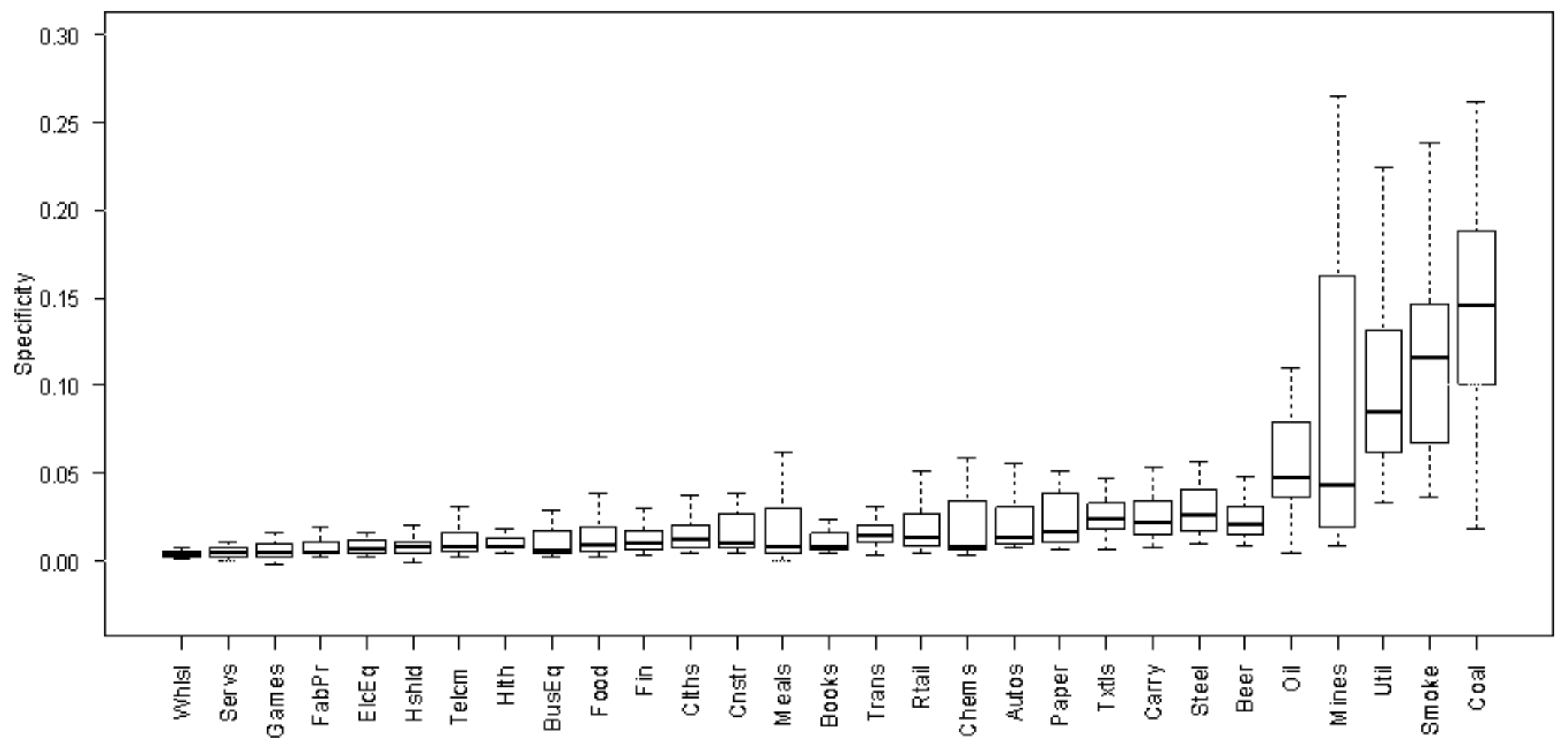


Table 1. Summary of industry exposure by industry

Column (1) presents the industry mean of the firm-specific estimates of the monthly industry factor betas $\left(\beta^{\text {ind }}\right)$ and column (2) presents the intra-industry standard deviation of $\beta^{\text {ind }}$. In column (3), $\delta_{\text {ind }}$ is the estimated industry factor exposure in year $y+1$ for a portfolio that buys high-industryexposure firms and shorts low-industry-exposure firms. $* * *\{* *\}[*]$ indicates significance at the $0.01\{0.05\}[0.10]$ level based on robust standard errors.

\begin{tabular}{|c|c|c|c|c|}
\hline Industry & $\begin{array}{l}\text { No. of firm-year } \\
\text { obs. in industry }\end{array}$ & $\begin{array}{c}(1) \\
\text { Industry mean of } \\
\beta^{\text {ind }}\end{array}$ & $\begin{array}{c}\text { (2) } \\
\text { Intra-industry } \\
\text { std dev of } \beta^{\text {ind }}\end{array}$ & $\begin{array}{l}(3) \\
\delta_{\text {ind }}\end{array}$ \\
\hline Electrical Equipment & 1,465 & 0.5232 & 1.2628 & 0.3295 \\
\hline Telecommunications & 2,494 & 0.5312 & 1.0324 & $0.3510 * * *$ \\
\hline Games & 2,660 & 0.5720 & 1.2353 & $0.5536 * * *$ \\
\hline Wholesale & 4,359 & 0.5802 & 1.6622 & 0.1986 \\
\hline Household & 2,082 & 0.5887 & 1.2395 & $0.6009 * * *$ \\
\hline Books & 1,394 & 0.6304 & 1.1722 & 0.1146 \\
\hline Meals & 1,890 & 0.6433 & 1.1710 & $0.2732 * *$ \\
\hline Smoke & 123 & 0.6439 & 0.8429 & $0.2558 * *$ \\
\hline Coal & 145 & 0.6452 & 0.7907 & $0.4228 * * *$ \\
\hline Construction & 3,542 & 0.6501 & 1.3512 & $0.6607 * * *$ \\
\hline Transportation & 2,645 & 0.6578 & 1.0351 & $0.7340 * * *$ \\
\hline Beer & 310 & 0.6636 & 1.1015 & $0.7095 * * *$ \\
\hline Carry & 680 & 0.6771 & 1.0209 & $0.4214 * *$ \\
\hline Chemicals & 1,730 & 0.6905 & 1.0482 & $0.4060 * * *$ \\
\hline Autos & 1,403 & 0.6913 & 1.0697 & $0.4046 * * *$ \\
\hline Food & 2,242 & 0.7060 & 1.3223 & $0.4384 * * *$ \\
\hline Clothes & 1,499 & 0.7097 & 1.3554 & $0.2600 * *$ \\
\hline Textiles & 685 & 0.7160 & 0.9776 & $0.8104 * *$ \\
\hline Paper & 1,990 & 0.7358 & 1.1544 & $0.5441^{* * *}$ \\
\hline Services & 11,597 & 0.7686 & 2.0116 & $0.8482 * * *$ \\
\hline Steel & 1,559 & 0.7696 & 0.8655 & $0.6450 * * *$ \\
\hline Fabricated Products & 4,330 & 0.7864 & 1.5607 & $0.6008 * * *$ \\
\hline Financial & 23,262 & 0.8395 & 1.5710 & $0.4566^{* * *}$ \\
\hline Health & 9,739 & 0.8531 & 1.4970 & $0.6866 * * *$ \\
\hline Retail & 5,343 & 0.8588 & 1.3229 & $0.4191 * * *$ \\
\hline Mines & 1,569 & 0.8859 & 0.8476 & $0.6104 * * *$ \\
\hline Oil & 4,113 & 0.9055 & 0.8754 & $0.5102 * * *$ \\
\hline Business Equipment & 13,656 & 0.9301 & 1.8013 & $0.8376 * * *$ \\
\hline Utilities & 3,658 & 0.9349 & 0.7023 & $0.7991 * * *$ \\
\hline
\end{tabular}


Table 2. Industry exposure and institutional ownership

Panel A presents average annual coefficient estimates from a regression of institutional ownership on industry factor price exposure and firm, stock, and industry characteristics. Institutional ownership is measured as the natural log of one plus the number of institutions that hold stock $i$ at the end of year $y$ (LNUMINST). Industry exposure is measured using the continuous variable $\beta^{\text {ind }}$ and using indicator variables that equal one if a firm's industry factor price exposure is greater (less) than the $70^{\text {th }}\left(30^{\text {th }}\right)$ percentile exposure (BETAHIGH and BETALOW). Percentiles for each industry are recalculated for each calendar year. Firm-specific control variables measured at or for the year ended $y-1$ are the natural logarithm of the market value of equity (LOGSIZE_MVE), the inverse price ratio (INVPRICE), the natural logarithm of the market-to-book ratio (LOGMB), dividend yield (DIVYLD), debt equity ratio (DERATIO), turnover (TURNOVER), price impact as a measure of liquidity (PRICEIMPACT), stock return volatility (RETVOL), and average monthly firm returns ( $L A G F I R M R E T$ ). Control variables measured at or for the year ended $y$ are stock market beta (MKTBETA2), firm age (FIRMAGE), and indicator variables for S\&P 500 stocks (S\&P500) and Nasdaq-listed stocks (NASDAQ). The models include industry returns over the calendar year $y-1$ (PASTINDRET) and year $y+1$ (FUTINDRET). Appendix A provides variable definitions. Models are estimated annually from 1984 through 2006. Panel B presents the average annual excess weight placed on high- and low-exposure stocks in institutional investor portfolios over the period from 1984 to 2006. The excess weights (XS-BETAHIGH and XS-BETALOW) are calculated relative to the value-weighted percentage of stocks with high and low industry exposure, respectively, within each industry each year. $* * *\{* *\}[*]$ indicates significance at the $0.01\{0.05\}[0.10]$ level, based on a test statistic computed from the distribution of yearly coefficients, adjusted for serial correlation.

\begin{tabular}{|c|c|c|}
\hline \multicolumn{3}{|c|}{ Panel A: Firm-level tests of the number of institutional investors } \\
\hline & $(1)$ & $(2)$ \\
\hline Intercept & $0.8341^{* * *}$ & $1.0601^{* * *}$ \\
\hline LOGSIZE_MVE & $0.3824^{* * *}$ & $0.3908^{* * *}$ \\
\hline INVPRICĒ & $0.2380^{* * *}$ & $0.2452^{* * *}$ \\
\hline LOGMB & $-0.0786^{* * * *}$ & $-0.0833^{* * *}$ \\
\hline DIVYLD & $-0.7692^{*}$ & $-0.7738^{* *}$ \\
\hline DERATIO & $-0.0117^{* * *}$ & $-0.0078^{* * *}$ \\
\hline TURNOVER & $0.1242^{* * *}$ & $0.1369^{* * *}$ \\
\hline PRICEIMPACT & $-0.2155^{* * * *}$ & $-0.2228^{* * *}$ \\
\hline RETVOL & -1.6380 & -0.8007 \\
\hline MKTBETA2 & $0.1652^{* * *}$ & $0.0610^{* * *}$ \\
\hline LAGFIRMRET & $1.1286^{* * *}$ & $1.2270^{* * *}$ \\
\hline FIRMAGE & $0.1936^{* * *}$ & $0.1891^{* * *}$ \\
\hline S\&P500 & $0.6122^{* * *}$ & $0.5856^{* * *}$ \\
\hline NASDAQ & $-0.2376^{* * *}$ & $-0.2444^{* * *}$ \\
\hline PASTINDRET & $0.1800^{* * *}$ & $0.2016^{* * *}$ \\
\hline FUTINDRET & -0.0384 & -0.0242 \\
\hline$\beta^{\text {ind }}$ & $0.2276^{* * *}$ & \\
\hline BETALOW & & $-0.2180^{* * *}$ \\
\hline BETAHIGH & & $\underline{0.1349^{* * *}}$ \\
\hline Difference & & $\overline{0.3529}$ \\
\hline No. of years significant: & & $22 / 23$ years \\
\hline Average annual number of observations & 2,651 & 2,651 \\
\hline Average annual Adjusted $\mathrm{R}^{2}$ & $76.07 \%$ & $75.69 \%$ \\
\hline \multicolumn{3}{|c|}{ Panel B: Institution-level tests of excess portfolio weights } \\
\hline$X S-B E T A L O W$ & $-0.0142^{* * *}$ & \\
\hline XS-BETAHIGH & $0.0138^{* * *}$ & \\
\hline
\end{tabular}


Table 3. Sensitivity of models of institutional ownership to alternative measures of industry exposure Average annual coefficient estimates from regressions of institutional ownership on industry factor price exposure and firm, stock, and industry characteristics, estimated using alternative measures of industry exposure. Panel A (B) present results for the continuous (discrete) measures of industry exposure. Institutional ownership is measured as the natural $\log$ of one plus the number of institutions that hold stock $i$ at the end of year $y$ (LNUMINST). In column (1), we present the results from Table 2 using $\beta^{\text {ind }}$ as the proxy for industry exposure for convenient comparison. Column (2) presents results using the absolute value of $\beta^{\text {ind }}$. In columns (3) through (5), $\beta^{\text {ind }}$ is derived using an alternative factor price model. The top rows of the table indicate the model specification including the weighting for the returns, the factors included, and the frequency of the data. All models include control variables described in Table 2 and defined in Appendix A. The coefficient estimates for the control variables are not tabulated. Models are estimated annually from 1984 through 2006. $* * *\{* *\}$ [*] indicates significance at the $0.01\{0.05\}$ [0.10] level, based on a test statistic computed from the distribution of yearly coefficients, adjusted for serial correlation.

\begin{tabular}{|c|c|c|c|c|c|}
\hline \multicolumn{6}{|c|}{ Panel A: Firm-level tests using continuous measures of industry exposure } \\
\hline & \multicolumn{5}{|c|}{ Alternative measure of industry exposure } \\
\hline & $\begin{array}{l}\text { Benchmark } \\
\text { model from } \\
\text { Table } 2\end{array}$ & $\begin{array}{l}\text { Industry } \\
\text { exposure = } \\
\left|\beta^{\text {ind }}\right|\end{array}$ & $\begin{array}{l}\beta^{\text {ind }} \text { from } \\
\text { market model } \\
\text { that includes } \\
\text { Fama-French } \\
\text { factors }\end{array}$ & $\begin{array}{l}\beta^{\text {ind }} \text { from eqn } \\
\text { (1) estimated } \\
\text { with value- } \\
\text { weighted } \\
\text { industry and } \\
\text { market returns }\end{array}$ & $\begin{array}{l}\beta^{\text {ind }} \text { from eqn } \\
\text { (1) estimated } \\
\text { monthly }\end{array}$ \\
\hline & $(1)$ & $(2)$ & (3) & $(4)$ & $(5)$ \\
\hline$\beta^{\text {ind }}$ & $0.2276^{* * *}$ & & $0.1517^{* * *}$ & $0.2848^{* * * *}$ & $0.1046^{* * *}$ \\
\hline$\left|\beta^{\text {ind }}\right|$ & & $0.0674^{* * *}$ & & & \\
\hline Control variables & YES & YES & YES & YES & YES \\
\hline Avg \# annual obs & 2,651 & 2,651 & 2,651 & 2,434 & 2,651 \\
\hline Avg ann Adj $R^{2}$ & $76.07 \%$ & $75.27 \%$ & $75.61 \%$ & $84.13 \%$ & $75.32 \%$ \\
\hline \multicolumn{6}{|c|}{ Panel B: Firm-level tests using indicator variables for industry exposure } \\
\hline BETALOW & $-0.2180^{* * *}$ & $-0.1040^{* * *}$ & $-0.2003^{* * *}$ & $-0.1700^{* * *}$ & $-0.1287^{* * *}$ \\
\hline BETAHIGH & $0.1349^{* * *}$ & $0.0548^{* * *}$ & $0.0895^{* * *}$ & $0.1354^{* * *}$ & 0.0166 \\
\hline Difference & 0.3529 & 0.1588 & 0.2898 & 0.3054 & 0.1453 \\
\hline Control variables & YES & YES & YES & YES & YES \\
\hline
\end{tabular}


Table 4. Exploration of alternative explanations for institutional ownership in industry exposure

Average annual coefficient estimates from regressions of institutional ownership on industry factor price exposure and firm, stock, and industry characteristics. The models are estimated separately within characteristic-sorted portfolios based on firm-specific risk (Panel A), financial reporting transparency (Panel B), liquidity (Panel C), and firm size (Panel D). Firm-specific risk is measured as the residual standard deviation from the extended market model in eqn (1). Transparency is measured as one minus the firm's revenue-based concentration ratio, computed following Comment and Jarrell (1995). Liquidity is measured as the Amihud (2002) price impact measure. Firm size is measured as the natural log of the market value of equity. For each characteristic, firms are ranked into quartiles within industry by year to determine the portfolio. Institutional ownership is measured as the natural log of one plus the number of institutions that hold stock $i$ at the end of year $y$ (LNUMINST). Industry exposure is measured using indicator variables that equal one if a firm's industry factor price exposure is greater (less) than the $70^{\text {th }}\left(30^{\text {th }}\right)$ percentile exposure (BETAHIGH and BETALOW). Percentiles for each industry are recalculated for each calendar year. All models include control variables described in Table 2 and defined in Appendix A (untabulated). Models are estimated annually from 1984 through 2006. $* * *\{* *\}[*]$ indicates significance at the $0.01\{0.05\}[0.10]$ level, based on a test statistic computed from the distribution of yearly coefficients, adjusted for serial correlation. The table denotes the number of years in which the annual difference between BETAHIGH and BETALOW is significant at the $10 \%$ level.

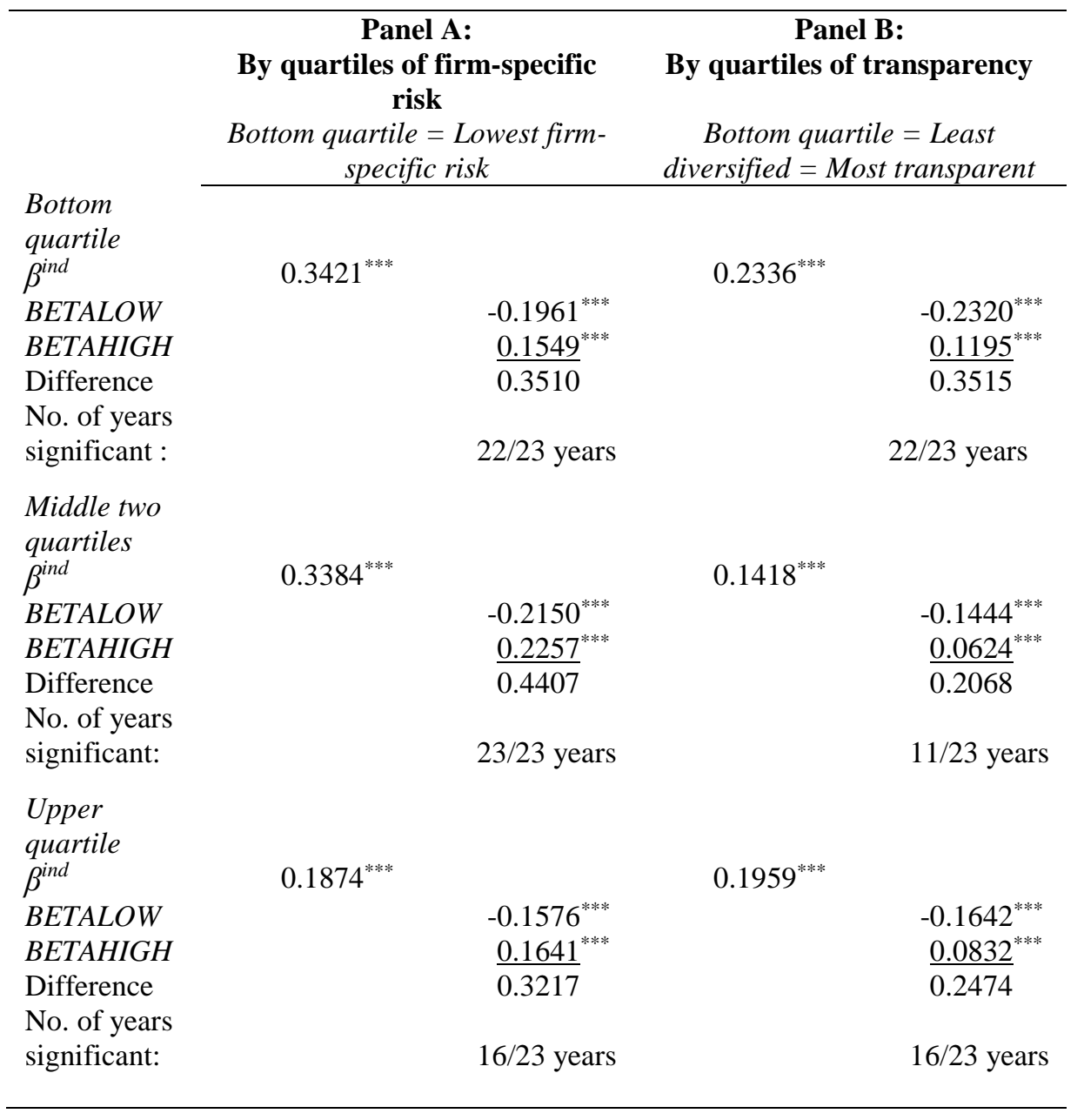




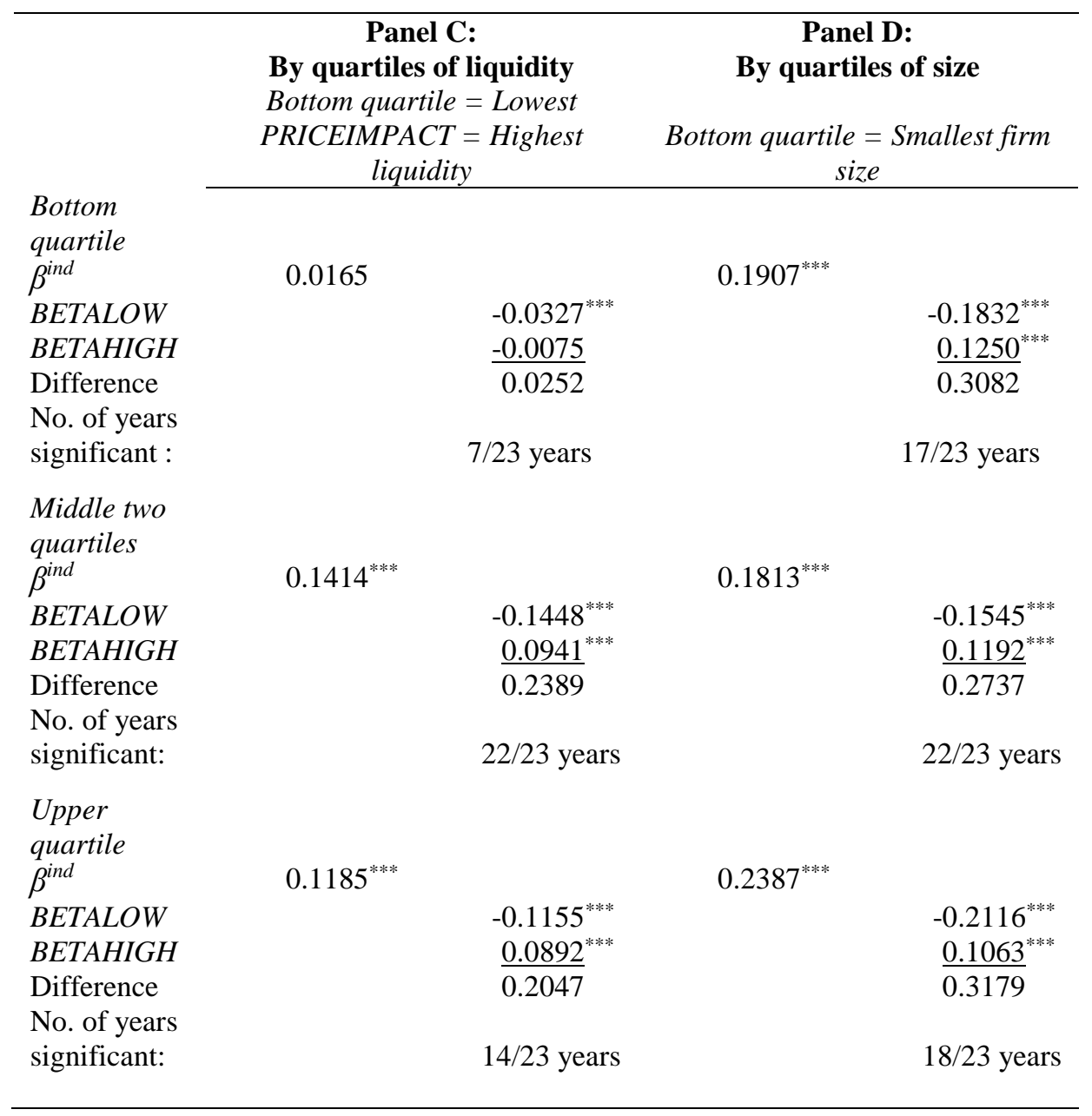


Table 5. Industry exposure and stock liquidity

Average annual coefficient estimates from models of share turnover and price impact as a function of industry exposure. Share turnover (TURNOVER) is the natural logarithm of average monthly turnover (volume divided by shares outstanding) computed for each firm $i$ in each year $y$. Price impact (PRICEIMPACT) is Amihud's illiquidity measure (truncated at 99th percentile). Industry factor price exposure is measured using the continuous variable $\beta^{\text {ind }}$ and using indicator variables that equal one if a firm's industry factor price exposure is greater (less) than the $70^{\text {th }}\left(30^{\text {th }}\right)$ percentile exposure (BETAHIGH and BETALOW). Percentiles for each industry are recalculated for each calendar year. The control variables are defined in Table 2 and Appendix A. TURNOVER and PRICEIMPACT are excluded as control variables. Models are estimated annually from 1984 through 2006 . *** $\{* *\}[*]$ indicates significance at the $0.01\{0.05\}[0.10]$ level, based on a test statistic computed from the distribution of yearly coefficients, adjusted for serial correlation.

\begin{tabular}{|c|c|c|c|c|}
\hline \multicolumn{5}{|l|}{ DEPENDENT } \\
\hline \multirow{2}{*}{ VARIABLE: } & \multicolumn{2}{|c|}{ TURNOVER } & \multicolumn{2}{|c|}{$\log ($ PRICEIMPACT $)$} \\
\hline & (1) & (2) & (3) & (4) \\
\hline Intercept & $-4.2454^{* * *}$ & $-3.9743^{* * *}$ & $2.1285^{* * *}$ & $1.6357^{* * *}$ \\
\hline LOGSIZE_MVE & $0.1305^{* * *}$ & $0.1590^{* * *}$ & $-0.9451^{* * *}$ & $-0.9870^{* * *}$ \\
\hline INVPRICE & $-0.1176^{* * * *}$ & $-0.1097^{* * * *}$ & $-0.3463^{* * *}$ & $-0.3613^{* * *}$ \\
\hline LOGMB & $0.0393^{* * *}$ & $0.0330^{* * *}$ & $-0.1075^{* * *}$ & $-0.0972^{* * *}$ \\
\hline DIVYLD & $-2.5073^{* * *}$ & $-2.7121^{* * *}$ & $-1.4391^{*}$ & -1.0937 \\
\hline DERATIO & $-0.0203^{* * *}$ & $-0.0129^{* * *}$ & $0.0315^{* * *}$ & $0.0192^{* * *}$ \\
\hline RETVOL & $8.4648^{* * * *}$ & $10.3066^{* * *}$ & $10.4503^{* * *}$ & $7.4498^{* * *}$ \\
\hline MKTBETA2 & $0.3809^{* * *}$ & $0.1444^{* * *}$ & $-0.5647^{* * *}$ & $-0.2154^{* * *}$ \\
\hline LAGFIRMRET & $2.0138^{* * *}$ & $2.2560^{* * *}$ & $-7.6994^{* * * *}$ & $-8.0858^{* * * *}$ \\
\hline FIRMAGE & $-0.0714^{* * *}$ & $-0.0851^{* * *}$ & $-0.1916^{* * *}$ & $-0.1719^{* * *}$ \\
\hline S\&P500 & $0.2263^{* * *}$ & $0.1719^{* * *}$ & $-1.2425^{* * *}$ & $-1.1523^{* * *}$ \\
\hline NASDAQ & $0.2246^{* * *}$ & $0.2053^{* * *}$ & $0.5545^{* * *}$ & $0.5716^{* * *}$ \\
\hline PASTINDRET & 0.0191 & 0.0474 & $-0.3664^{* * *}$ & $-0.4169^{* * *}$ \\
\hline FUTINDRET & -0.1397 & -0.1125 & 0.1451 & $0.0996^{* * *}$ \\
\hline$\beta^{\text {ind }}$ & $0.5029^{* * *}$ & & $-0.7389^{* * *}$ & \\
\hline BETALOW & & $-0.2878^{* * *}$ & & $0.6095^{* * * *}$ \\
\hline BETAHIGH & & ${\underline{0.4522^{* * *}}}$ & & $\underline{-0.4734^{* * *}}$ \\
\hline Difference & & 0.7400 & & -1.0829 \\
\hline No. of years significant & & $23 / 23$ years & & $22 / 23$ years \\
\hline Average annual $\mathrm{N}$ & 2,666 & 2,666 & 2,665 & 2,665 \\
\hline Average annual & & & & \\
\hline Adjusted $\mathrm{R}^{2}$ & $32.35 \%$ & $27.59 \%$ & $75.24 \%$ & $74.22 \%$ \\
\hline
\end{tabular}


Table 6. Industry exposure and institutional ownership conditional on past industry returns

Panel A presents average annual coefficient estimates from a regression of institutional ownership on industry factor price exposure, and firm, stock and industry characteristics. The models include past industry returns interacted with measures of industry exposure. Institutional ownership is measured as the natural $\log$ of one plus the number of institutions that hold stock $i$ at the end of year $y$ (LNUMINST). In column (1), industry exposure is measured using the continuous variable $\beta^{\text {ind }}$. In column (2), industry factor price exposure is measured using indicator variables that equal one if a firm's industry factor price exposure is greater (less) than the $70^{\text {th }}\left(30^{\text {th }}\right)$ percentile exposure (BETAHIGH and BETALOW). Percentiles for each industry are calculated for each calendar year. All models include control variables described in Table 2 and defined in Appendix A; only estimates for PASTINDRET are tabulated. The model in column (1) includes interaction terms that are the products of $\beta^{\text {ind }}$ and indicator variables for high (low) returns, defined as above (below) the $75^{\text {th }}\left(25^{\text {th }}\right)$ percentile of annual returns within the industry. The model in column (2) includes interaction terms that are the product of the continuous measure of past industry returns (PASTINDRET) and the indicator variables BETAHIGH and BETALOW. Models are estimated annually from 1984 through 2006. Panel B presents the average annual excess weight placed on high- and low-exposure stocks in institutional investor portfolios. The averages are measured separately over periods of high, medium, and low past industry returns. The excess weights (XS-BETAHIGH and XS-BETALOW) are calculated relative to the value-weighted percentage of stocks with high and low industry exposure, respectively, within each industry each year. $* * *\{* *\}[*]$ indicates significance at the $0.01\{0.05\}[0.10]$ level, based on a test statistic computed from the distribution of yearly coefficients, adjusted for serial correlation.

\begin{tabular}{lcc}
\hline \multicolumn{2}{l}{ Panel A: Firm-level tests of the number of institutional investors conditional on past industry returns } \\
\hline & $(1)$ & $(2)$ \\
PASTINDRET & $0.1473^{* * * *}$ & $0.1922^{* * * *}$ \\
$\beta^{\text {ind }}$ & $0.2244^{* * *}$ & \\
$\beta^{\text {ind }} \times$ LOWPASTINDRET & -0.0075 & \\
$\beta^{\text {ind }}$ x HIGHPASTINDRET & $0.0254^{* *}$ & $-0.2258^{* * * *}$ \\
BETALOW & & $0.0919^{* * *}$ \\
BETAHIGH & & $-0.1148^{*}$ \\
BETALOW $x$ PASTINDRET & & $0.1450^{* *}$ \\
BETAHIGH $x$ PASTINDRET & & 2,651 \\
Average annual number of observations & & $75.74 \%$ \\
Average annual Adjusted R & &
\end{tabular}

Panel B: Institution-level tests of excess portfolio weights conditional on past industry returns

Past industry returns

\begin{tabular}{clc} 
High & Medium & Low \\
\hline-0.0015 & $0.0093^{*}$ & 0.0010 \\
$0.0258^{* *}$ & $0.0211^{* * *}$ & $0.0157^{* * *}$ \\
\hline
\end{tabular}




\section{Table 7. Cross-sectional variation in institutional ownership based on industry homogeneity}

Panel A presents average annual coefficient estimates from regressions of institutional ownership on industry factor price exposure, and firm, stock, and industry characteristics, estimated separately for three categories of stocks: High, medium, and low homogeneity. Industry homogeneity $(H O M O G E N E I T Y)$ is the difference between the adjusted $\mathrm{R}^{2}$ values from estimation of a standard market model and an extended market model for each firm $i$ within industry $j$, estimated using monthly return data over the period January of year $y-4$ to December of year $y$. The extended market model includes the appropriate equally weighted industry returns and the equally weighted market returns. Institutional ownership is measured as the natural log of one plus the number of institutions that hold stock $i$ at the end of year $y$ (LNUMINST). Industry exposure is measured using the continuous variable $\beta^{\text {ind }}$ and using indicator variables that equal one if a firm's industry factor price exposure is greater (less) than the $70^{\text {th }}\left(30^{\text {th }}\right)$ percentile exposure (BETAHIGH and BETALOW). Percentiles for each industry are recalculated for each calendar year. All models include control variables described in Table 2 and defined in Appendix A. The coefficient estimates for the control variables are not tabulated Models are estimated annually from 1984 through 2006. Panel B presents the average annual excess weight placed on high- and low-exposure stocks in institutional investor portfolios averaged over the period from 1984 through 2006. The excess weights (XS-BETAHIGH and XS-BETALOW) are calculated relative to the valueweighted percentage of stocks with high and low industry exposure, respectively, within each industry each year. $* * *\{* *\}[*]$ indicates significance at the 0.01 $\{0.05\}[0.10]$ level, based on a test statistic computed from the distribution of yearly coefficients, adjusted for serial correlation.

\begin{tabular}{|c|c|c|c|c|c|c|}
\hline & \multicolumn{6}{|c|}{ Panel A: Firm-level tests of the number of institutional investors } \\
\hline & \multicolumn{3}{|c|}{ HOMOGENEITY } & \multicolumn{3}{|c|}{ HOMOGENEITY } \\
\hline & $(1)$ & $(2)$ & (3) & (4) & (5) & (6) \\
\hline & High & Medium & Low & High & Medium & Low \\
\hline$\beta^{\text {ind }}$ & $0.2794^{* * *}$ & $0.2381^{* * *}$ & $0.1809^{* * *}$ & & & \\
\hline BETALOW & & & & $-0.2495^{* * *}$ & $-0.2320^{* * *}$ & $-0.1472^{* * *}$ \\
\hline BETAHIGH & & & & $0.1141^{* * *}$ & $\underline{0.1437}^{* * *}$ & ${\underline{0.0857^{* * *}}}^{* n_{0}}$ \\
\hline Difference & & & & $\overline{0.3636}$ & $\overline{0.3757}$ & $\overline{0.2329}$ \\
\hline No. of years significant: & & & & $18 / 23$ years & $23 / 23$ years & $16 / 23$ years \\
\hline Average annual $\mathrm{N}$ & 263 & 1,850 & 538 & 263 & 1,850 & 538 \\
\hline \multirow[t]{2}{*}{ Average annual Adjusted R ${ }^{2}$} & $81.69 \%$ & $76.61 \%$ & $71.21 \%$ & $81.60 \%$ & $76.16 \%$ & $70.92 \%$ \\
\hline & \multicolumn{6}{|c|}{ Panel B: Institution-level tests of excess portfolio weights } \\
\hline$X S-B E T A L O W$ & $-0.0601^{* *}$ & $-0.0105^{* * *}$ & 0.0050 & & & \\
\hline XS-BETAHIGH & $0.0388^{* * *}$ & $0.0139^{* * *}$ & -0.0042 & & & \\
\hline
\end{tabular}




\section{Table 8. Cross-sectional variation in institutional investor preferences based on 13F designation}

Results for institutions by Thomson 13F designations: banks, insurance companies, investment advisors, and pensions/endowments. Panel A presents average annual coefficient estimates from multivariate models of institutional ownership as a function of industry exposure. Institutional ownership is measured as the natural log of one plus the number of institutions of a particular type that hold stock $i$ at the end of year $y$ (LNUMINST). Industry exposure is measured using the continuous variable $\beta^{\text {ind }}$ and using indicator variables that equal one if a firm's industry factor price exposure is greater (less) than the $70^{\text {th }}$ ( $30^{\text {th }}$ ) percentile exposure (BETAHIGH and BETALOW). Percentiles for each industry are recalculated for each calendar year. All models include control variables described in Table 2 and defined in Appendix A (untabulated). Models are estimated annually from 1984 through 2006. The coefficient estimates presented are the averages of the annual estimates. $(*)\{* *\}[* * *]$ indicate statistical significance at the $(10 \%)\{5 \%\}[1 \%]$ level. Significance levels are based on a Z-statistic associated with the annual tstatistics (see Table 2). Parenthetical amounts represent the number of annual test statistics that are significant at the $10 \%$ level in the 23 annual regressions. Panel $\mathrm{B}$ presents the results estimated separately for high and low homogeneity industries. Panel C presents the portfolio tilting test results. XS-BETAHIGH and XSBETALOW represent the excess weight calculated relative to the value-weighted percentage of stocks with high and low industry exposure, respectively, within each industry each year. We present the average annual excess weight placed on high and low exposure stocks in institutional investor portfolios over the period from 1984 to 2006.

\begin{tabular}{|c|c|c|c|c|c|c|c|c|}
\hline \multicolumn{9}{|c|}{ Panel A: Firm-level tests of the number of institutional investors by Thomson 13F designations } \\
\hline \multirow{6}{*}{$\begin{array}{l}\beta^{\text {ind }} \\
\text { BETALOW } \\
\text { BETAHIGH }\end{array}$} & $(1)$ & (2) & (3) & (4) & (5) & (6) & \multirow{2}{*}{$\begin{array}{c}(7) \\
\text { Investment } \\
\text { Advisors }\end{array}$} & \multirow{2}{*}{$\begin{array}{c}\text { (8) } \\
\text { Pensions/ } \\
\text { Endowments }\end{array}$} \\
\hline & Banks & $\begin{array}{l}\text { Insurance } \\
\text { Companies }\end{array}$ & $\begin{array}{c}\text { Investment } \\
\text { Advisors }\end{array}$ & $\begin{array}{c}\text { Pensions/ } \\
\text { Endowments }\end{array}$ & Banks & $\begin{array}{l}\text { Insurance } \\
\text { Companies }\end{array}$ & & \\
\hline & $0.1697^{* * *}$ & $0.1929^{* * *}$ & $0.2133^{* * *}$ & $0.1860^{* * *}$ & & & & \\
\hline & & & & & $-0.1622^{* * * *}$ & $-0.1754^{* * *}$ & $-0.2108^{* * *}$ & $-0.1797^{* * *}$ \\
\hline & & & & & $0.1007^{* * *}$ & $0.1277^{* * *}$ & $0.1292^{* * *}$ & $0.1271^{* * *}$ \\
\hline & & & & & 0.2629 & 0.3031 & 0.3400 & 0.3068 \\
\hline No. of years significant: & & & & & $22 / 23$ years & $22 / 23$ years & $23 / 23$ years & $22 / 23$ years \\
\hline Average annual $\mathrm{N}$ & 2,651 & 2,651 & 2,651 & 2,651 & 2,651 & 2,651 & 2,651 & 2,651 \\
\hline Average annual Adjusted $\mathrm{R}^{2}$ & $75.32 \%$ & $71.12 \%$ & $73.64 \%$ & $73.37 \%$ & $75.03 \%$ & $70.69 \%$ & $73.31 \%$ & $73.10 \%$ \\
\hline \multicolumn{9}{|c|}{ Panel B: Firm-level tests of the number of institutional investors by Thomson $13 \mathrm{~F}$ designations and industry homogeneity } \\
\hline & \multicolumn{4}{|c|}{ High homogeneity industries } & \multicolumn{4}{|c|}{ Low homogeneity industries } \\
\hline & Banks & $\begin{array}{l}\text { Insurance } \\
\text { Companies }\end{array}$ & $\begin{array}{l}\text { Investment } \\
\text { Advisors }\end{array}$ & $\begin{array}{c}\text { Pensions/ } \\
\text { Endowments }\end{array}$ & Banks & $\begin{array}{l}\text { Insurance } \\
\text { Companies }\end{array}$ & $\begin{array}{l}\text { Investment } \\
\text { Advisors }\end{array}$ & $\begin{array}{c}\text { Pensions/ } \\
\text { Endowments }\end{array}$ \\
\hline BETALOW & $-0.1866^{* * *}$ & $-0.2563^{* * * *}$ & $-0.2346^{* * * *}$ & $-0.2475^{* * *}$ & $-0.0791^{* * *}$ & $-0.1065^{* * *}$ & $-0.1626^{* * *}$ & $-0.1038^{* * *}$ \\
\hline BETAHIGH & ${\underline{0.0977^{* * *}}}^{* * 1}$ & $\underline{0.1166}^{* * *}$ & $\underline{0.1087^{* * *}}$ & $\underline{0.1389}^{* * *}$ & ${\underline{0.0465^{* * *}}}^{* *}$ & ${\underline{0.0585^{* * *}}}^{* *}$ & $\underline{0.0893}^{* * *}$ & $\underline{0.0349}^{* * *}$ \\
\hline Difference & $\overline{0.2843}$ & 0.3729 & 0.3433 & 0.3864 & $\overline{0.1256}$ & $\overline{0.1650}$ & $\overline{0.2519}$ & $\overline{0.1387}$ \\
\hline Test vs. Banks & & $\begin{array}{c}(19 / 25) \\
(6 / 23)\end{array}$ & $(8 / 23)$ & $\begin{array}{c}(1 / / 23) \\
(6 / 23)\end{array}$ & & $\begin{array}{c}(11 / 23) \\
(5 / 23)\end{array}$ & $\begin{array}{l}(16 / 23) \\
(12 / 23)\end{array}$ & $\begin{array}{c}(12 / 23) \\
(4 / 23)\end{array}$ \\
\hline Test vs. Insurance companies & & & $(5 / 23)$ & $(2 / 23)$ & & & $(6 / 23)$ & $(2 / 23)$ \\
\hline Test vs. Investment advisors & & & & $(6 / 23)$ & & & & $(9 / 23)$ \\
\hline
\end{tabular}


Table 8, continued

\begin{tabular}{|c|c|c|c|c|c|c|}
\hline \multicolumn{7}{|c|}{ Panel C: Institutional-level tests of excess portfolio weights by Thomson 13F designations } \\
\hline & \multicolumn{2}{|c|}{ All industries } & \multicolumn{2}{|c|}{ High homogeneity industries } & \multicolumn{2}{|c|}{ Low homogeneity industries } \\
\hline & $X S-B E T A H I G H$ & $X S-B E T A L O W$ & $X S-B E T A H I G H$ & $X S-B E T A L O W$ & $X S-B E T A H I G H$ & $X S-B E T A L O W$ \\
\hline Banks & $-0.0156^{* * *}$ & $-0.0120^{* * *}$ & 0.0051 & -0.0099 & $-0.0509^{* * *}$ & 0.0179 \\
\hline Insurance Companies & $0.0098^{* * *}$ & $-0.0178^{* * *}$ & $0.0234^{* *}$ & $-0.0526^{* * *}$ & $-0.0154^{* * *}$ & 0.0089 \\
\hline Investment Advisors & $0.0222^{* * *}$ & $-0.0134^{* * *}$ & $0.0491^{* * *}$ & $-0.0721^{* *}$ & $0.0103^{* * *}$ & 0.0009 \\
\hline Pensions/Endowments & $0.0135^{* * *}$ & $-0.0222^{* * *}$ & $0.0487^{* * *}$ & $-0.0885^{* * *}$ & $-0.0163^{* * *}$ & 0.0082 \\
\hline
\end{tabular}


Table 9. Cross-sectional variation in institutional investor preferences based on institutional investor style

Results for institutions classified based on the Bushee (1998) trading style classifications: Dedicated owners, quasi-indexers, and transient investors. Panel A presents average annual coefficient estimates from multivariate models of institutional ownership as a function of industry exposure. Institutional ownership is measured as the natural log of one plus the number of institutions of a particular type that hold stock $i$ at the end of year $y$ (LNUMINST). Industry exposure is measured using the continuous variable $\beta^{\text {ind }}$ and using indicator variables that equal one if a firm's industry factor price exposure is greater (less) than the $70^{\text {th }}$ ( $30^{\text {th }}$ ) percentile exposure (BETAHIGH and BETALOW). Percentiles for each industry are recalculated for each calendar year. All models include control variables described in Table 2 and defined in Appendix A (untabulated). Models are estimated annually from 1984 through 2006. The coefficient estimates presented are the averages of the annual estimates. $(*)\{* *\}[* * *]$ indicate statistical significance at the $(10 \%)\{5 \%\}$ [1\%] level. Significance levels are based on a Z-statistic associated with the annual t-statistics (see Table 2). Parenthetical amounts represent the number of annual test statistics that are significant at the $10 \%$ level in the 23 annual regressions. Panel B presents the results estimated separately for high and low homogeneity industries. Panel C presents the portfolio tilting test results. XS-BETAHIGH and XS-BETALOW represent the excess weight calculated relative to the value-weighted percentage of stocks with high and low industry exposure, respectively, within each industry each year. We present the average annual excess weight placed on high and low exposure stocks in institutional investor portfolios over the period from 1984 to 2006.

\begin{tabular}{|c|c|c|c|c|c|c|}
\hline \multicolumn{7}{|c|}{ Panel A: Firm-level tests of the number of institutional investors by investment style } \\
\hline & (1) & $(2)$ & (3) & (4) & (5) & (6) \\
\hline & $\begin{array}{c}\text { Dedicated } \\
\text { Owners }\end{array}$ & Quasi-indexers & $\begin{array}{l}\text { Transient } \\
\text { Investors }\end{array}$ & $\begin{array}{c}\text { Dedicated } \\
\text { Owners }\end{array}$ & Quasi-indexers & $\begin{array}{l}\text { Transient } \\
\text { Investors }\end{array}$ \\
\hline$\beta^{\text {ind }}$ & $0.0747^{\text {*** }}$ & $0.2042^{* * *}$ & $0.2526^{* * *}$ & & & \\
\hline BETALOW & & & & $-0.0895^{* * *}$ & $-0.2031^{* * *}$ & $-0.2216^{* * *}$ \\
\hline BETAHIGH & & & & ${\underline{0.0385^{* * *}}}^{* * 1}$ & $\underline{0.1152^{* * *}}$ & $\underline{0.1752^{* * *}}$ \\
\hline Difference & & & & $\overline{0.1280}$ & $\overline{0.3183}$ & $\overline{0.3968}$ \\
\hline No. of years significant: & & & & $18 / 23$ years & $22 / 23$ years & $23 / 23$ years \\
\hline Average annual $\mathrm{N}$ & 2,651 & 2,651 & 2,651 & 2,651 & 2,651 & 2,651 \\
\hline Average annual Adjusted $\mathrm{R}^{2}$ & $61.66 \%$ & $75.58 \%$ & $72.17 \%$ & $61.58 \%$ & $75.26 \%$ & $71.64 \%$ \\
\hline
\end{tabular}

\begin{tabular}{|c|c|c|c|c|c|c|}
\hline \multicolumn{7}{|c|}{ Panel B: Firm-level tests of the number of institutional investors by investment style and industry homogeneity } \\
\hline & \multicolumn{3}{|c|}{ High homogeneity industries } & \multicolumn{3}{|c|}{ Low homogeneity industries } \\
\hline & $\begin{array}{c}\text { Dedicated } \\
\text { Owners }\end{array}$ & Quasi-indexers & $\begin{array}{l}\text { Transient } \\
\text { Investors }\end{array}$ & $\begin{array}{c}\text { Dedicated } \\
\text { Owners }\end{array}$ & Quasi-indexers & $\begin{array}{l}\text { Transient } \\
\text { Investors }\end{array}$ \\
\hline BETALOW & $-0.1059^{* * *}$ & $-0.1429^{* * *}$ & $-0.2608^{* * *}$ & -0.0099 & $-0.0466^{* * *}$ & $-0.0350^{* *}$ \\
\hline BETAHIGH & ${\underline{0.0511^{* *}}}^{*}$ & $\underline{0.0696}^{* * *}$ & $\underline{0.1138}^{* * *}$ & $-0.0361^{* * *}$ & $\underline{-0.0283}$ & $\underline{-0.0143}$ \\
\hline Difference & 0.1570 & 0.2125 & $\overline{0.3746}$ & $\overline{-0.0262}$ & 0.0183 & 0.0207 \\
\hline \# of annual sig differences & $(14 / 23)$ & $(17 / 23)$ & $(21 / 23)$ & $(3 / 23)$ & $(4 / 23)$ & $(4 / 23)$ \\
\hline Test vs. Dedicated Owners & & $(3 / 23)$ & $(12 / 23)$ & & $(2 / 23)$ & $(4 / 23)$ \\
\hline Test vs. Quasi-indexers & & & $(13 / 23)$ & & & $(4 / 23)$ \\
\hline
\end{tabular}


Table 9, continued

\begin{tabular}{|c|c|c|c|c|c|c|}
\hline \multicolumn{7}{|c|}{ Panel C: Institutional-level tests of excess portfolio weights by investment style } \\
\hline & \multicolumn{2}{|c|}{ All industries } & \multicolumn{2}{|c|}{ High homogeneity industries } & \multicolumn{2}{|c|}{ Low homogeneity industries } \\
\hline & XS-BETAHIGH & $X S-B E T A L O W$ & XS-BETAHIGH & $X S-B E T A L O W$ & $X S-B E T A H I G H$ & $X S-B E T A L O W$ \\
\hline \multicolumn{7}{|l|}{ Investment Style } \\
\hline Dedicated Owners & $0.0087^{*}$ & $0.0076^{*}$ & $0.0220^{* *}$ & -0.0002 & $0.0256^{* * *}$ & -0.0011 \\
\hline Quasi-indexers & -0.0013 & $-0.0103^{* * *}$ & 0.0207 & -0.0398 & $-0.0268^{* * *}$ & $-0.0143^{* *}$ \\
\hline Transient Investors & $0.0462^{2 * *}$ & $-0.0267^{* * *}$ & $0.0796^{* * *}$ & $-0.1138^{* * *}$ & $0.0354^{* * *}$ & -0.0125 \\
\hline
\end{tabular}




\section{Appendix A: Control variable definitions}

We draw the control variable constructs for the determinants of institutional ownership from four sources: Del Guercio (1996), Falkenstein (1996), Gompers and Metrick (2001), and Hong and Kacperczyk (2009). We winsorize all control variables except for firm age and the indicator variables for inclusion in the S\&P 500 index and Nasdaq stocks at the first and $99^{\text {th }}$ percentiles.

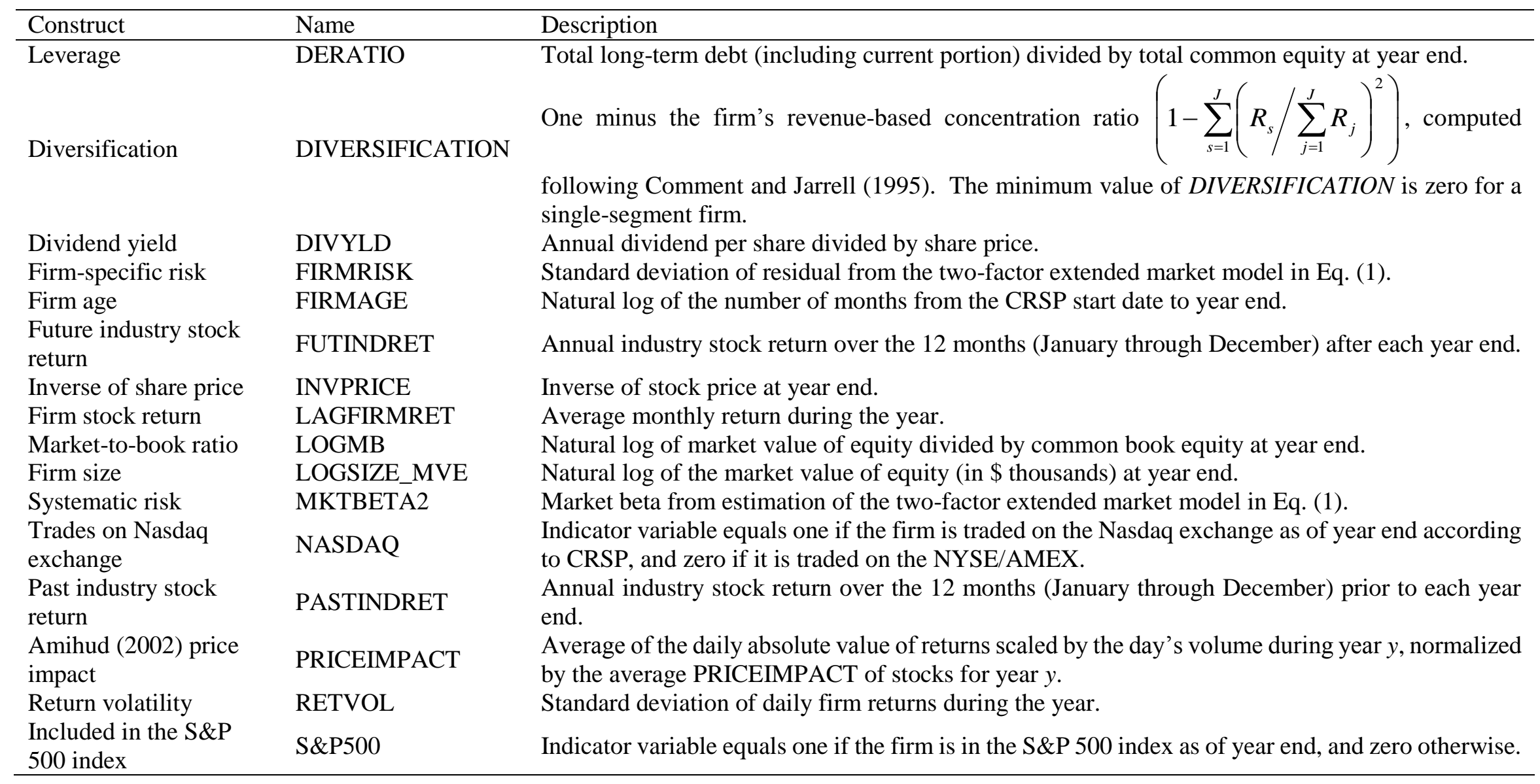




\section{Appendix B}

\section{Table B1. Summary statistics for dependent and control variables}

Means and medians of the natural log of one plus the number of institutions that hold stock $i$ at the end of year $y$ (LNUMINST), and regression control variables: the natural logarithm of the market value of equity ( $L O G S I Z E \_M V E$ ), the inverse price ratio (INVPRICE), the natural logarithm of the market-to-book ratio $(L O G M B)$, dividend yield (DIVYLD), debt equity ratio (DERATIO), turnover (TURNOVER), price impact as a measure of liquidity (PRICEIMPACT), stock return volatility (RETVOL), average monthly firm returns (LAGFIRMRET), stock market beta (MKTBETA2), firm age (FIRMAGE), and indicator variables for S\&P 500 stocks (S\&P500) and Nasdaq-listed stocks (NASDAQ). The means and medians are for the sample of firms used to estimate eqn. (3) in Table 2 across the years 1984 - 2006.

\begin{tabular}{llcc}
\hline & & Mean & Median \\
\cline { 3 - 4 } Log number of institutional investors & LNUMINST & 3.5616 & 3.5835 \\
Firm size (Log MV of equity) & LOGSIZE_MVE & 5.3740 & 5.2828 \\
Inverse of share price & INVPRICE & 0.1790 & 0.0620 \\
Log market-to-book ratio & LOGMB & 0.5218 & 0.4550 \\
Dividend yield & DIVYLD & 0.0164 & 0.0033 \\
Leverage (Debt/equity ratio) & DERATIO & 1.1946 & 0.6433 \\
Log monthly turnover & TURNOVER & -2.9641 & -2.9235 \\
Amihud (2002) price impact & PRICEIMPACT & 0.2875 & 0.0130 \\
Daily return volatility & RETVOL & 0.0314 & 0.0259 \\
Systematic risk & MKTBETA2 & 0.2368 & 0.1969 \\
Average monthly return & LAGFIRMRET & 0.0142 & 0.0125 \\
Log firm age in months & FIRMAGE & 4.9543 & 5.0106 \\
S\&P 500 index inclusion dummy & S\&P500 & 0.1296 & 0.0000 \\
Nasdaq firm indicator & NASDAQ & 0.4848 & 0.0000 \\
\hline
\end{tabular}




\section{Appendix C: Sensitivity of models of institutional ownership to an alternative measure of industry exposure conditional on macro-economic risk factor exposure}

As an alternative to our primary measure of industry exposure $\left(\beta^{\text {ind }}\right)$, we generate an exposure measure using a market model that includes macro-economic risk factors:

$$
r_{i m}=\alpha_{i y}+\beta_{i y}^{m k t} r_{m k t, m}+\varphi_{i y}^{i n d} r_{i n d, m}+\sum_{z=1}^{7} \delta_{i y}^{z} F A C T O R_{z m}+\xi_{i m}
$$

where $r_{m k t}$ and $r_{\text {ind }}$ are the monthly returns on the appropriate equally weighted market and industry portfolios, respectively, and $F A C T O R_{z}$ is one of seven risk factors identified in prior research:

1. Interest Rates (INT): Calculated as the 3 month treasury bill rate.

2. Default Premium (DEF): Calculated as Moody's Seasoned Baa Corporate Bond Yield - 10 year government bond yield.

3. Term Premium (TERM): Calculated as the yield on 10 year constant maturity government bonds - the yield on one year constant maturity government bonds.

4. Foreign Exchange Rates (FX): A weighted average of the foreign exchange value of the U.S. dollar against a subset of the broad index currencies that circulate widely outside the country of issue.

5. Commodities (COM): We use the Producer Price Index for Commodities provided by the Bureau of Labor Statistics.

6. Small minus Big (SMB): The Fama-French monthly benchmark factor for the performance of small stocks relative to big stocks.

7. High book-to-market - low book-to-market (HML): The Fama-French monthly benchmark factor for the performance of value stocks relative to growth stocks (High Minus Low).

We estimate eqn. (C1) for each firm $i$ at the end of each year $y$ from 1984 through 2006 using the past 60 months of monthly return data.

We estimate a version of eqn. (3) - the model of institutional ownership - using $\varphi_{i y}^{i n d}$ as the measure of industry exposure, including all control variables with $\beta^{m k t}$ estimated in eqn. (C1), and including the macro-risk parameters from eqn. $\mathrm{C} 1$ (the $\delta$ 's). The coefficients on the control variables are similar to the results reported in Table 2 in terms of sign, magnitude, and statistical significance and are not reported. Table $\mathrm{C} 1$ shows that industry exposure remains a positive and significant determinant of institutional ownership at the $1 \%$ level in all models. 


\section{Table C1: Industry exposure, factor price exposure, and institutional ownership}

Average annual coefficient estimates from models of industry factor price exposure as a determinant of institutional ownership in a firm's stock. Institutional ownership is measured as the natural log of one plus the number of institutions that hold stock $i$ at the end of year $y$ (LNUMINST). Industry factor price exposure is measured using the continuous variable $\varphi^{\text {ind }}$ estimated in eqn. (C1). The models include the exposure coefficient estimates on seven risk factors: $S M B, H M L$, INT, TERM, DEF, FX, and COM. Firm-specific control variables measured at or for the year ended $y-1$ are the natural logarithm of the market value of equity ( $\left.L O G S I Z E \_M V E\right)$, the inverse price ratio (INVPRICE), the natural logarithm of the market-to-book ratio (LOGMB), dividend yield (DIVYLD), debt equity ratio (DERATIO), turnover (TURNOVER), price impact as a measure of liquidity (PRICEIMPACT) stock return volatility (RETVOL), and average monthly firm returns (LAGFIRMRET). Control variables measured at or for the year ended $y$ are stock market beta (MKTBETA2), firm age (FIRMAGE), and indicator variables for S\&P 500 stocks $(S \& P 500)$ and Nasdaq-listed stocks $(N A S D A Q)$. The models include industry returns over the calendar year $y-1$ (PASTINDRET) and year $y+1$ (FUTINDRET). Models are estimated annually from 1984 through 2006. *** $\{* *\}[*]$ indicates significance at the $0.01\{0.05\}$ [0.10] level, based on a test statistic computed from the distribution of yearly coefficients, adjusted for serial correlation.

(1)

$0.1403^{* * *}$

0.0009

$-0.0193$

$-0.0011$

$-0.0009$

$-0.0117^{*}$

$-0.0097$

$-0.0025$
(2)
$0.1068^{* * *}$

$0.1040^{* * *}$

$0.1073^{\text {*** }}$

$0.1066^{* * * *}$

$0.1049^{* * * *}$

Exposure to additional factors:

$\delta^{\mathrm{HML}}$

$\delta^{\mathrm{INT}}$

$\delta^{\text {TERM }}$

$\delta^{\mathrm{FX}}$

$\delta^{\mathrm{COM}}$

Control variables

Average annual \# of obs

Avg annual Adj-R ${ }^{2}$

\section{$-0.0049$}

$-0.0207^{* *}$

$-0.0046$

$-0.0006$

$-0.0047^{\text {** }}$

$-0.0058$

$-0.0025$
YES

2,434

$84.47 \%$

\section{YES}

2,434

$83.64 \%$

\section{YES}

2,434

$83.74 \%$

\section{YES}

2,434

$83.73 \%$

\section{YES}

2,434

$83.68 \%$

\section{YES}

2,434

$83.70 \%$
YES

2,434

$83.63 \%$
YES

2,434

$83.61 \%$ 